\title{
Retinoic acid and arsenic trioxide in the treatment of acute promyelocytic leukemia: current perspectives
}

This article was published in the following Dove Press journal:

OncoTargets and Therapy

14 March 2017

Number of times this article has been viewed

\author{
Derek McCulloch \\ Christina Brown \\ Harry lland \\ Institute of Hematology, \\ Royal Prince Alfred Hospital, \\ Camperdown, NSW, Australia
}

Correspondence: Derek McCulloch Institute of Haematology, Royal Prince Alfred Hospital, Missenden Road, Camperdown, NSW 2050, Australia Email doctordexmcculloch@yahoo.co.uk

\begin{abstract}
Acute promyelocytic leukemia (APL) is a distinct subtype of acute myeloid leukemia (AML) with a unique morphological appearance, associated coagulopathy and canonical balanced translocation of genetic material between chromosomes 15 and 17. APL was first described as a distinct subtype of AML in 1957 by Dr Leif Hillestad who recognized the pattern of an acute leukemia associated with fibrinolysis, hypofibrinogenemia and catastrophic hemorrhage. In the intervening years, the characteristic morphology of APL has been described fully with both classical hypergranular and variant microgranular forms. Both are characterized by a balanced translocation between the long arms of chromosomes 15 and 17, [t(15;17)(q24;q21)], giving rise to a unique fusion gene $P M L-R A R A$ and an abnormal chimeric transcription factor (PML-RARA), which disrupts normal myeloid differentiation programs. The success of current treatments for APL is in marked contrast to the vast majority of patients with non-promyelocytic AML. The overall prognosis in non-promyelocytic AML is poor, and although there has been an improvement in overall survival in patients aged $<60$ years, only $30 \%-40 \%$ of younger patients are still alive 5 years after diagnosis. APL therapy has diverged from standard AML therapy through the empirical discovery of two agents that directly target the molecular basis of the disease. The evolution of treatment over the last 4 decades to include all-trans retinoic acid and arsenic trioxide, with chemotherapy limited to patients with high-risk disease, has led to complete remission in $90 \%-100 \%$ of patients in trials and rates of overall survival between $86 \%$ and $97 \%$.
\end{abstract}

Keywords: acute promyelocytic leukemia, ATRA, arsenic trioxide

\section{Background}

The discovery of acute promyelocytic leukemia (APL) arose from early case reports of patients who presented with an acute leukemia and bleeding preponderance. Building on these published case reports, Dr Hillestad identified the common characteristics of this new and rapidly fatal disease. ${ }^{1-5}$ A subsequent more detailed report on 20 patients treated at the Hôpital St Louis in Paris by Jean Bernard increased early understanding of this unique disease. ${ }^{6}$ APL accounts for 3\%-13\% of acute myeloid leukemia (AML) based on data from UK and Swedish registries. ${ }^{7,8}$ It has been reported that the incidence of APL is higher in populations originating from Central and South America, where APL may constitute $28 \%$ of AML cases. ${ }^{9,10}$

The characteristic morphology of APL has been described fully; first, the typical or hypergranular form of APL with characteristically abnormal promyelocytes exhibiting a densely granulated cytoplasm, Auer rods or Faggot cells (cells with bundles of Auer rods) and a nuclear membrane that is often reniform or bilobed. ${ }^{11}$ A microgranular 
variant associated with a high white cell count (WCC) and predominantly bilobed nuclei was described later. ${ }^{12}$ Both forms were found to be associated with a balanced translocation between the long arms of chromosomes 15 and $17,[\mathrm{t}(15 ; 17)(\mathrm{q} 24 ; \mathrm{q} 21)]$, giving rise to a unique fusion gene $P M L-R A R A .^{13,14}$ There are rarer cryptic and complex cytogenetic rearrangements that have been identified giving rise to a $P M L-R A R A$ fusion; furthermore, variant gene fusion partners for the RARA gene not involving the $P M L$ locus have been described. The 2016 update of the WHO classification of myeloid neoplasms and myeloid malignancies specifically describes APL with $P M L-R A R A$ to distinguish it from these other entities. ${ }^{15,16}$ AML is recognized as a heterogenous disease, often with co-existing somatic mutations, contributing to its clonal evolution, relapse and poor overall survival (OS). In contrast, APL appears to be a less heterogeneous disease with a smaller portfolio of associated genetic mutations and thus a greater sensitivity to therapy. A recent mutational analysis of primary and relapse APL cases identified mutations in genes for Fms-like tyrosine kinase 3 (FLT3), Wilms tumor 1 (WT1) and $N$-RAS most commonly. However, mutations in genes recognized as recurring sites of genetic mutations in AML such as DNMT3A, NPM1, IDH1/2, RUNX1, TP53, TET2 and CEBPA are absent or rarely present. ${ }^{17}$

The success of current treatments for APL is unparalleled and in marked contrast to the vast majority of patients with non-promyelocytic AML who can expect a 5-year OS of $30 \%-40 \%,{ }^{18-21}$ although it is accepted that patients diagnosed with AML with the so-called favorable cytogenetic rearrangements $\mathrm{t}(8 ; 21)(\mathrm{q} 22 ; \mathrm{q} 22.1) ; R U N X 1-R U N X 1 T 1, \operatorname{inv}(16)$ (p13.1q22) or $\mathrm{t}(16 ; 16)(\mathrm{p} 13.1 ; \mathrm{q} 22) ; C B F B-M Y H 11$ have a 5-year OS between 55\% and 69\%. ${ }^{22-24}$ Similarly, patients with normal cytogenetics and concurrent mutations in the nucleophosmin-1 (NPM1) gene (without FLT3 internal tandem duplications [ITDs]) or those possessing bi-allelic mutations of CEBPA can expect a 5-year OS between $50 \%$ and $70 \% .^{25-34}$

APL therapy has evolved through the empirical discovery of two agents that directly target the molecular foundation of the disease. The evolution of treatment over 4 decades to include all-trans retinoic acid (ATRA), arsenic trioxide (ATO) and chemotherapy in a variety of protocols has led to complete remission (CR) in $90 \%-100 \%$ of patients in trials and rates of OS between $86 \%$ and $97 \% .{ }^{35-42}$

\section{Chemotherapy era}

The first therapeutic breakthrough in the treatment of APL was the introduction of anthracyclines. Prior to this, early case reports showed that only $6 \%-14 \%$ entered remission and the majority of patients died within 4 weeks. ${ }^{43-45}$ In 1973 , Bernard et $\mathrm{al}^{46}$ reported in a review of 80 patients that daunorubicin as monotherapy increased CR rates from $13 \%$ to $55 \%$. The effectiveness of anthracycline-based treatment was subsequently confirmed by European and North American researchers, including the use of an anthracycline as a single agent. These studies showed CR rates between $55 \%$ and $88 \%$, with $35 \%-45 \%$ of patients entering a prolonged remission. ${ }^{47-56}$ The effectiveness of anthracyclinebased treatment appeared to be dose dependent, with higher doses of daunorubicin improving remission rates. ${ }^{57}$ Thus, in the pre-ATRA era, patients diagnosed with APL typically underwent chemotherapy induction with an anthracycline and cytarabine, eg, the "7-3" regimen, similar to non-APL AML. However, unlike non-APL AML, there was no demonstrable benefit in APL when cytarabine was added to an anthracycline during induction therapy in APL. $48,50,58$

\section{ATRA era}

The concept of differentiation therapy arose from an improved understanding of cancer cell biology, such as the demonstration by Breitman et $\mathrm{al}^{59}$ that ATRA and 13-cis retinoic acid could induce differentiation in the HL-60 myeloid leukemia cell line. ATRA was subsequently shown to induce differentiation of leukemic cells in culture more potently than 13-cis retinoic acid. ${ }^{60,61}$ The PML-RARA fusion protein forms homodimers, recruits co-repressors and sequesters the normal RARA heterodimeric partner, retinoid $\mathrm{X}$ receptor-alpha. The complex binds to genes involved in myeloid differentiation, blocking their transcription. Retinoic acid in pharmacological doses binds to PML-RARA inducing a conformational change, allowing the dissociation of co-repressors and activating gene transcription and cellular differentiation. ${ }^{62}$ Retinoic acid also induces PML-RARA degradation through recruitment of proteases (including caspases) and proteasomes; furthermore, this degradation pathway appears to be distinct to that required to induce differentiation. ${ }^{63-68}$

Following isolated case reports, Huang et a ${ }^{69}$ published the successful treatment of APL with ATRA in 24 patients, with $>90 \% \mathrm{CR}$ and no exacerbation of coagulopathy or early death due to hemorrhage. The efficacy of ATRA was confirmed by Laurent Degos' group in Paris. ${ }^{70,71}$ However, ATRA alone could not induce a prolonged remission as seen in the initial studies that demonstrated that despite maintenance therapy with ATRA or low-dose chemotherapy, the majority of patients relapsed within 6 months. ${ }^{70,72,73}$ 
Researchers also noted a clinical syndrome caused by ATRA-induced differentiation of leukemic cells. Differentiation syndrome (DS), as it became known, can manifest with unexplained fever, hypotension, weight gain $(>5 \mathrm{~kg})$, respiratory distress, pulmonary infiltrates, pleural and/or pericardial effusions and renal failure. ${ }^{74,75}$ The pathogenesis of DS has not been well defined; the hypothesis derived from research in primary culture and using cell lines suggests a systemic inflammatory response driven by the release of proinflammatory cytokines, with endothelial damage, capillary leak and alterations in cellular adhesion molecule expression leading to tissue infiltration by leukemic cells and microcirculation occlusion. ${ }^{76,77}$ The risk of DS is greatest in patients who present with or develop a raised white cell count (WCC) with treatment. Thus, regimens that include the myelotoxic effects of chemotherapy taken concurrently with ATRA help reduce the risk of rising WCC and DS. The standard accepted management once DS is recognized is treatment with corticosteroids, eg, dexamethasone $10 \mathrm{mg}$ twice daily intravenously (IV) until resolution and for at least 3 days. ${ }^{78}$ The use of prophylactic steroid therapy during induction shows a beneficial reduction in the incidence of DS, although no randomized studies have been reported. ${ }^{38,39,79-81}$

Intensive anthracycline-based chemotherapy in combination with ATRA demonstrated excellent results in early non-randomized and later randomized trials. The prospective randomized European APL91 trial that compared three cycles of chemotherapy with or without ATRA was stopped early due to the significant improvement in event-free survival (EFS) in the ATRA therapy cohort. ${ }^{82,83}$ The EFS at 12 months in the ATRA-treated group was $79 \%$ compared to $50 \%$ in the chemotherapy-treated cohort $(P=0.001)$, and after a 4 -year follow-up, the EFS in the ATRA group was $63 \%$ compared to $17 \%$ in the chemotherapy-only cohort. The follow-up APL93 trial demonstrated a benefit to commencing chemotherapy simultaneously with ATRA as opposed to ATRA followed by sequential chemotherapy. The study also included a maintenance randomization and compared no maintenance, low-dose chemotherapy with 6-mercaptopurine (6-MP) and methotrexate, and ATRA 15 days every 3 months minus or plus low-dose chemotherapy. The rates of relapse at 2 years were $27 \%, 11 \%, 13 \%$ and $7.4 \%$, respectively. ${ }^{84}$

Subsequently, ATRA in combination with chemotherapy was investigated by multiple groups with $\mathrm{CR}$ rates between $72 \%$ and $95 \% .{ }^{85-90}$ The Gruppo Italiano Malattie Ematologiche dell'Adulto (GIMEMA) used an ATRA/idarubicin (AIDA) induction and added three cycles of consolidation containing idarubicin, cytarabine, etoposide, mitoxantrone and thioguanine. The resulting AIDA0493 protocol achieved a 95\% CR rate, 2-year EFS of $79 \%$ and OS of $87 \%{ }^{89,90}$ The Spanish Programa Espãnol de Tratamientos en Hematología (PETHEMA) LPA96 trial successfully demonstrated that removing all non-anthracycline drugs from the consolidation phase after an AIDA-based induction did not significantly affect patient outcomes with a CR rate of 89\%, 2-year EFS of $79 \%$ and OS of $82 \% .{ }^{85}$ Similarly, the Australasian Leukaemia and Lymphoma Group (ALLG) APML3 trial used an AIDA induction backbone and an additional second cycle of idarubicin. The CR rate was $86 \%$, and the importance of maintenance in this setting was shown by separate cohorts treated with or without maintenance, 4-year disease-free survival (DFS) $78.9 \%$ vs $46.9 \%$, respectively. ${ }^{91}$

Since the combined data from the AIDA0493 and LPA096 trials had identified no benefit from the use of nonanthracycline drugs during consolidation, a joint analysis was undertaken that identified the WCC and platelet count as reliable predictors of relapse, after achievement of a CR. This heralded the era of risk-adapted therapy with the socalled Sanz criteria (Table 1). ${ }^{92}$

Subsequently, risk-stratified trials based on an AIDA induction backbone demonstrated a benefit of ATRA in consolidation for all patients (LPA99 trial) and cytarabine in consolidation for high-risk patients (LPA2005 and AIDA2000 trials). ${ }^{37,93,94}$ In the LPA2005 trial, high-risk patient treatment with cytarabine reduced the 3-year relapse rate from $26 \%$ to $11 \%(P=0.03)$ when compared to the results from the LPA99 trial, with an overall CR rate for all patients of $92.5 \% .^{37,94}$ Similarly, the AIDA2000 trial demonstrated that risk-adapted therapy in consolidation (ATRA for all patients, omission of non-anthracycline drugs for low/intermediate risk) resulted in all patients achieving better longer term outcomes. Lowintermediate risk patients suffered less toxicity and infection, while high-risk patients achieved a 6-year cumulative incidence of relapse (CIR) of $9.3 \%$ compared to $49.7 \%$ $(P<0.001)$ in the previous AIDA0493 trial. ${ }^{93}$

The benefit of cytarabine in consolidation therapy for high-risk patients was also demonstrated by the French APL2000 trial, where a CR rate of $97.3 \%$ with a 7-year CIR of $7.1 \%$, EFS of $82.2 \%$ and OS of $87.6 \%$ was achieved.

Table I Risk stratification in APL

\begin{tabular}{lll}
\hline Sanz risk category & WCC $\left(\times 10^{9} / \mathrm{L}\right)$ & Platelet count $\left(\times 10^{9} / \mathrm{L}\right)$ \\
\hline Low & $\leq 10$ & $>40$ \\
Intermediate & $\leq 10$ & $\leq 40$ \\
High & $>10$ & \\
\hline
\end{tabular}

Abbreviations: APL, acute promyelocytic leukemia; WCC, white cell count. 
The results in high-risk patients were comparable to those in low-intermediate risk patients who achieved a 7-year CIR of $12.9 \% .{ }^{95}$ A joint review of the results from the APL2000 and LPA99 trials confirmed a greater benefit for low-intermediate risk patients on an ATRA-idarubicinbased protocol and better survival for high-risk patients with more intense anthracycline and cytarabine consolidation. ${ }^{96}$ It was proposed that because the AIDA protocol contained a higher cumulative dose of anthracycline or drugs with anthracycline equivalency, it generated better responses in lower risk patients. ${ }^{97}$ In contrast, the UK MRC AML15 trial found no benefit to the inclusion of chemotherapy other than anthracyclines in the treatment of 285 patients who unsurprisingly experienced more toxicity and required an average of 19 more days in hospital. ${ }^{98}$

The result of this progressive improvement in the understanding of patients' risk and response was the European LeukaemiaNet recommendations for the management of APL. The expert panel advised induction based on an anthracycline/ATRA combination; a standard approach to consolidation should involve two to three cycles of anthracycline-based chemotherapy, intermediate- or highdose cytarabine should be included in those younger patients with a WCC $>10 \times 10^{9} / \mathrm{L}$ and that maintenance therapy should be used in patients treated with protocols in which maintenance has been shown to be of benefit. ${ }^{78}$

The success achieved through treatment with ATRA-anthracycline-based protocols is unparalleled in other AML, but concern regarding the long-term risk of anthracycline and other chemotherapy exposure remains. Secondary cytogenetic abnormalities such as therapy-related myelodysplasia/AML have a reported incidence between $0.97 \%$ and $6.5 \%$ in French and Italian patient groups, respectively, and 2.2\% at 6 years in all patients treated in the LPA96, LPA99 and LPA2005 trials who achieved CR. ${ }^{99-105}$ Anthracycline-related cardiotoxicity is also a concern ${ }^{106,107}$ as research has shown that patients treated on AIDA-based protocols developed subclinical but detectable diastolic dysfunction and regional wall motion abnormalities. ${ }^{106}$ Recognized common acute side effects associated with ATRA therapy include fever, rash, headache and pseudotumor cerebri; the latter occurs more commonly in adolescents/children and may prompt dose reduction or cessation of ATRA in severe cases. ${ }^{108}$ Long-term toxicity secondary to ATRA therapy has not been seen but requires ongoing review.

\section{The arsenic era}

Arsenic in various forms has been in use for $>2000$ years, by both Hippocrates in ancient Greece and in traditional Chinese medicine. ${ }^{109,110}$ Thomas Fowler's eponymous solution of ATO was used as a tonic for the treatment of a variety of ailments and was also used to treat leukemia in the late 19th and early 20 th centuries. ${ }^{11,112}$

In 1973, researchers in Harbin province developed a solution of ATO and mercury chloride named "Ailing I" also known as "Ai-Lin I", which they used to treat patients with acute and chronic leukemia. The successful treatment of patients with APL was reported initially in Chinese journals and was followed by a landmark publication in 1997, when researchers from Harbin and Shanghai described CR rates of $90 \%$ in patients with APL who had relapsed after ATRA and chemotherapy treatment and were treated with ATO as a single agent. ${ }^{113}$ The proposed mechanism of action for ATO was the dose-dependent induction of apoptosis or differentiation. ${ }^{114}$

Subsequent research has shown that arsenic's therapeutic efficacy is due to its effect on the PML moiety of the PMLRARA fusion protein. The normal PML protein is of fundamental importance for the formation of so-called nuclear bodies (NBs), which allow recruitment and interaction of proteins through the posttranslational modifications of sumoylation and ubiquitination. ${ }^{115} \mathrm{NBs}$ are disrupted in APL with consequent loss of their tumor-suppressive activity. Arsenic binds to the PML component of PML-RARA through two cysteine residues in the $\mathrm{B} 2$ domain of PML protein, inducing their oxidation, leading to disulfide bond formation. ${ }^{116,117}$ The subsequent reformation of PML-containing NBs allows sumoylation of the PML/PML-RARA protein, concomitant recruitment of a SUMO-dependent ubiquitin ligase (RNF4) and polyubiquitination. The final step is the degradation of the PML moiety and its associated RARA partner by the proteasome. ${ }^{18,119}$ Additionally, arsenic induces the degradation of PML/PML-RARA through the production of reactive oxygen species (ROS) that also produces oxidation of PML and formation of NBs. Since anthracyclines can also stimulate the production of ROS, there may a contributory role of anthracyclines in PML-RARA degradation. ${ }^{120}$ Thus, in combination ATRA and ATO target the degradation of PML-RARA through distinct interactions with the RARA or PML moieties, respectively. The result is a synergistic destruction of the fusion protein and eradication of leukemiainitiating cells (LICs). ${ }^{121,122}$

The efficacy of ATO in the relapse setting was confirmed in a pilot study in New York, where 11 of 12 extensively pretreated patients achieved a CR. A subsequent multicenter study of 40 patients in first or second relapse utilized ATO for induction, consolidation and maintenance therapy. The CR rate was $85 \%$, and the 18 -month OS and relapse-free 
survival (RFS) were $66 \%$ and $56 \%$, respectively. ${ }^{123,124}$ As the treatment of APL using ATRA-anthracycline-based protocols improved, ATO was shown to be an efficacious salvage treatment for relapse patients by numerous groups. ${ }^{125-130}$

The first successful trial of ATO in the treatment of newly diagnosed APL by Shen et al demonstrated that induction with ATO alone could induce CR in $90 \%$ of patients, whereas 95\% of patients treated with ATRA alone or ATRA plus ATO achieved CR. There was a significantly shorter time to $\mathrm{CR}$ for patients treated with ATO/ATRA vs ATRA alone (25.5 vs 40.5 days, $P=0.0003$ ). ${ }^{131}$ The protocol described by Shen et al contained moderately intensive consolidation therapy with three cycles of chemotherapy. ${ }^{131}$ Longer term follow-up shows a 5-year DFS for the ATO/ATRA cohort of $94.8 \%$ and OS of $91.7 \% .{ }^{132}$ Another Chinese study reported on 90 patients also induced with either ATRA or ATO/ ATRA who achieved CR rates of $90 \%$ vs $93 \%$, respectively $(P=0.56)$. The cohort of ATRA-induced patients was subsequently split and treated with traditional or ATO-containing consolidation/maintenance regimens. Replacing four of 10 cycles of chemotherapy in consolidation/maintenance with ATO increased the 3-year RFS from $72.4 \%$ to $92.9 \%$ $(P=0.048)$. A similar RFS rate of $92.6 \%$ was achieved in ATO/ATRA-induced patients, who also received ATOcontaining consolidation/maintenance. ${ }^{133}$

The benefits of ATO use in consolidation were borne out by results of the North American Leukemia Intergroup C9710 study, where $90 \%$ of patients achieved a CR after ATRA and chemotherapy, and were then randomized to either receive additional ATO consolidation (two cycles of $0.15 \mathrm{mg} / \mathrm{kg} /$ day for 5 days for 5 weeks) or progress to a common ATRA/daunorubicin consolidation. The addition of ATO increased the 3-year EFS from $63 \%$ to $80 \%$ $(P<0.0001)$ and 3 -year DFS for all patients from $70 \%$ to 90\% $(P<0.0001)$. Crucially, consolidation with ATO significantly improved DFS for both low-intermediate $(P<0.001)$ and high-risk patients $(P<0.0001)$ compared to those not receiving ATO consolidation. Furthermore, there was no statistically significant difference between the 3-year DFS achieved using ATO consolidation in low-intermediate and high-risk cohorts $(P=0.24){ }^{36}$

Subsequently, three groups of researchers attempted to investigate whether ATO as monotherapy or in combination with minimal doses of chemotherapy could successfully treat patients diagnosed with APL. Two independent groups based in Tehran and Vellore reported the results of trials employing ATO as a monotherapy during induction, consolidation and maintenance, with chemotherapy only given in the event of leukocytosis or DS. The overall CR rate achieved was $86 \%$ in both trials with DFS in the Indian cohort of $87 \%$ at 3 years vs $63.7 \%$ in the Iranian cohort at 2 years. ${ }^{134,135}$ The poorer outcomes from the Tehran study were likely due to lower ATO exposure in the initial Iranian regimen, and despite adding additional consolidation cycles to their schedule after 2006, Iranian patients received less ATO within the first 6 months compared to the Vellore patients. Follow-up results at 5 years showed a DFS and an OS for the Vellore vs Tehran cohorts of $80 \%$ vs $67 \%$ and $74 \%$ vs $64 \%$, respectively. ${ }^{136,137}$ Patients defined by the Vellore study criteria as good risk (WCC $<5 \times 10^{9} / \mathrm{L}$, platelets $>20 \times 10^{9} / \mathrm{L}$ ) had an EFS of $90 \%$ and OS of $100 \%$ compared to $60 \%$ and $63 \%$ in higher risk patients. Thus, ATO has impressive activity as a single agent but in higher risk patients, there still appeared a need for additional therapy. Furthermore, in combination with ATO, ATRA has been proposed to increase the expression of aquaglyceroporin 9, which facilitates increased ATO uptake. ${ }^{138}$

The combination of ATRA, ATO and gemtuzumab ozogamicin for high-risk patients or those with rising WCCs was trialed by researchers at the M.D. Anderson Cancer Center. Gemtuzumab ozogamicin is a humanized anti-CD33 monoclonal antibody covalently conjugated with a cytotoxic anti-tumor agent calicheamicin. Over 6 years, 82 patients were treated with a $\mathrm{CR}$ rate of $90 \%$ and a 3 -year estimated OS of $85 \% .^{35,139}$ The trial was small but demonstrated the potential benefits of the regimen, and the OS rates are similar to those of the LPA99 and C9710 trial of the same period without the use of traditional chemotherapeutic drugs or maintenance. ${ }^{36,94}$ However, high-risk patients and those aged $>60$ years still had poorer outcomes with OS rates of $69 \%$ and $73 \%$, respectively.

The ALLG APML4 trial rationalized the treatment of newly diagnosed patients to therapy with a combination of ATRA and ATO in combination with idarubicin in lower cumulative doses than those used in AIDA-based protocols. The aim of induction with ATRA, ATO and an anthracycline was to achieve the shortest time to remission and reduce the risks of hyperleukocytosis and DS. Aggressive hemostatic support and prophylactic prednisolone were included to reduce the rate of bleeding, DS and early death. The trial included consolidation therapy with ATRA/ATO and a 2-year maintenance regimen of ATRA, 6-MP and methotrexate proven to be of benefit in some previous studies. ${ }^{84,91}$ The early death rate was lower than in the APML3 trial, but not significantly so (3.2\% vs $7.1 \%$, $P=0.29$ ), while achieving a CR rate of $95 \%$ and a 2 -year DFS of $97.5 \% .{ }^{38}$ After a median follow-up of 4.2 years, there was a significant improvement in 5-year OS $(94 \%$, $P=0.02$; Figure 1), DFS $(95 \%, P=0.001$; Figure 2$)$ and EFS 


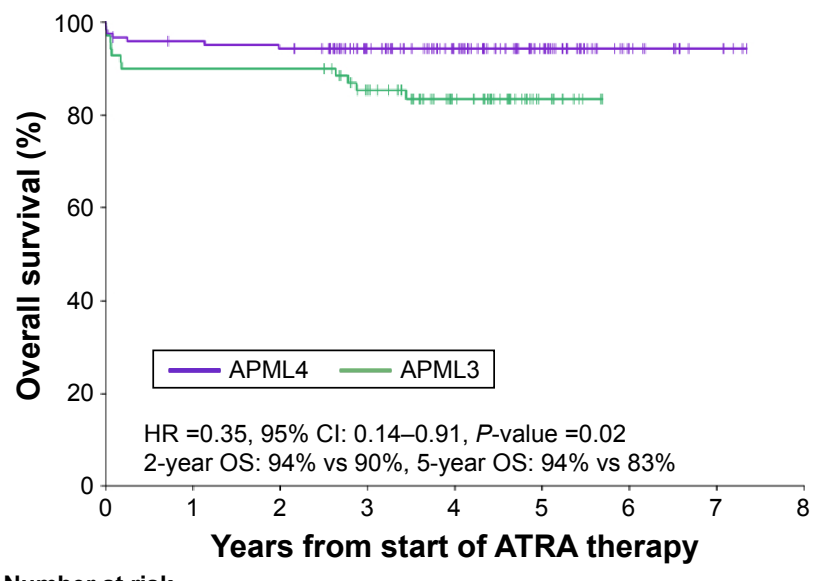

Number at risk

$\begin{array}{llllllllll}\text { APML4 } & 124 & 117 & 115 & 90 & 66 & 37 & 14 & 5 & 0\end{array}$

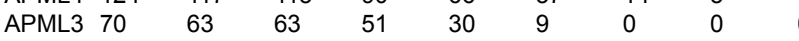

Figure I Comparison of OS in the ALLG APML4 and ALLG APML3 trials. Note: Figure was provided courtesy of $\mathrm{H}$ lland (APML4 principal investigator) from the Australasian Leukaemia and Lymphoma Group APML4 Statistical Report (June 2013) by Collins M, Di lulio J, and Beresford J (unpublished).

Abbreviations: OS, overall survival; ALLG, Australasian Leukaemia and Lymphoma Group; HR, hazard ratio; $\mathrm{Cl}$, confidence interval; ATRA, all trans-retinoic acid.

(90\%, $P=0.02)$ when compared to APML3. ${ }^{41}$ In addition, high-risk patients in the APML4 trial appeared to benefit as the freedom from relapse was not significantly different between risk groups (Figure 3). Furthermore, in high-risk patients, the 5 -year CIR was only $5 \%$, as compared to $11 \%$ at 3 years for the LPA2005 protocol, $9 \%$ at 6 years for AIDA2000 and $9.5 \%$ at 5 years for APL2000. ${ }^{37,80,93,96}$

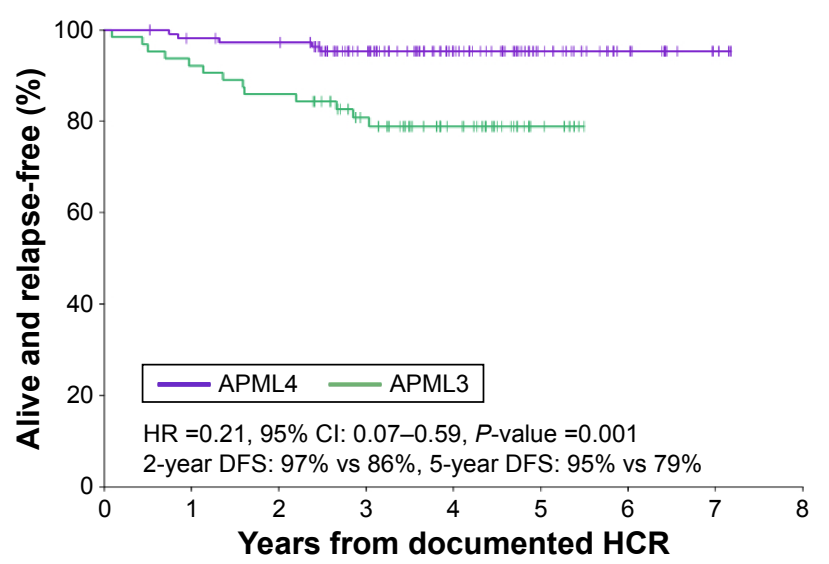

Number at risk

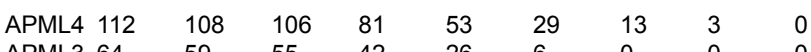

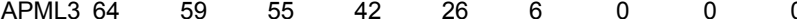

Figure 2 Comparison of DFS in the ALLG APML4 and ALLG APML3 trials.

Note: Figure was provided courtesy of $\mathrm{H}$ lland (APML4 principal investigator) from the Australasian Leukaemia and Lymphoma Group APML4 Statistical Report (June 20I3) by Collins M, Di lulio J, and Beresford J (unpublished).

Abbreviations: DFS, disease-free survival; ALLG, Australasian Leukaemia and Lymphoma Group; HR, hazard ratio; $\mathrm{Cl}$, confidence interval; $\mathrm{HCR}$, hematological complete remission.

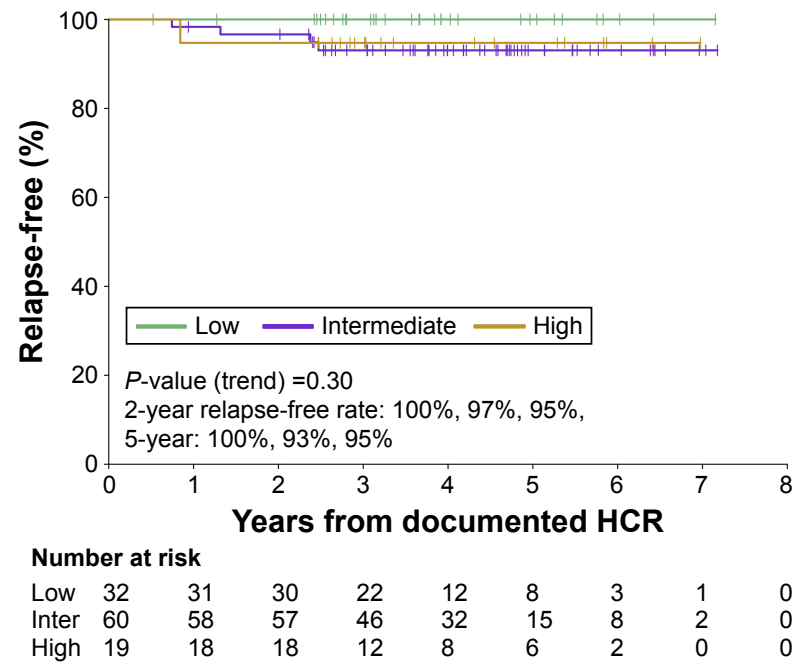

Figure 3 Estimated Kaplan-Meier curve for freedom from relapse from documented hematological CR in the APML4 trial, stratified by Sanz risk category.

Note: Figure was provided courtesy of $\mathrm{H}$ lland (APML4 principal investigator) from the Australasian Leukaemia and Lymphoma Group APML4 Statistical Report (June 20I3) by Collins M, Di lulio J, and Beresford J (unpublished).

Abbreviations: $\mathrm{CR}$, complete remission; $\mathrm{HCR}$, hematological complete remission.

These benefits were achieved without the addition of further moderate-high-dose chemotherapy during induction and/ or consolidation, as utilized in the PETHEMA, GIMEMA and APL group trials and led to the incorporation of the APML4 protocol into the Canadian APL management guidelines and the National Comprehensive Cancer Network guidelines for high-risk APL. ${ }^{140,141}$ Therefore, ATO + ATRA appeared to be an efficacious therapy for induction and consolidation in newly diagnosed APL, but randomized trials focusing on low/intermediate-risk vs high-risk APL were lacking.

The APL0406 trial, a prospective, randomized, Phase III, multicenter study of low-intermediate risk patients by the GIMEMA, German-Austrian Acute Myeloid Leukemia Study and Study Alliance Leukemia groups tested whether ATO and ATRA induction and consolidation without maintenance therapy was non-inferior to the established AIDA2000 protocol. The impressive results included ATO/ ATRA-treated patients achieving rates of CR, 2-year OS and 2-year EFS of 100\%, 99\% and 97\%, respectively, compared to $95 \%(P=0.12), 91 \%(P=0.02)$ and $86 \%$ in the AIDA arm $\left(P<0.001\right.$ for non-inferiority and $P=0.02$ for superiority). ${ }^{39}$ The most recently published follow-up data showed that the 50-month EFS, OS and CIR were $97.3 \%, 99.2 \%$ and $1.9 \%$ in the ATO/ATRA cohort vs $80 \%(P<0.01), 92.6 \%(P=0.0073)$ and $13.9 \%(P=0.0013)$ in the AIDA cohort, respectively. ${ }^{142}$ This study has helped define the current "Gold-Standard" treatment for low-intermediate risk APL. ${ }^{140,141}$ 
In the case of high-risk APL patients, the TUD-APOLLO064 (NCT02688140) trial may clarify management by comparing an AIDA2000-based high-risk treatment arm (minus etoposide and thioguanine) with an APL0406-based treatment with two additional doses of idarubicin during induction.

The UK National Cancer Research Institute (NCRI) AML17 trial randomized newly diagnosed APL patients to treatment with either AIDA induction and consolidation or ATRA combined with ATO given in a similar overall dose to that used in APL0406 but where more drug is given in the first week of the induction and consolidation cycles then less frequently in subsequent weeks. Fifty-seven high-risk patients were included (30 in the ATO/ATRA cohort), and gemtuzumab ozogamicin was also given to 28 of the 30 highrisk patients. The other two received additional idarubicin. The primary outcome of quality of life did not differ significantly between cohorts, but ATRA/ATO patients required less supportive care in the first two cycles of therapy as compared to the AIDA cohort. ${ }^{40}$ In terms of secondary outcomes, CR was achieved in $89 \%$ of the AIDA cohort vs $94 \%$ for ATRA/ATO $(P=0.18)$. In comparison between the ATRA/ ATO and AIDA patients, there was significant improvement in 4-year EFS, $91 \%$ vs $70 \%(P=0.002)$, cumulative incidence of morphological relapse $1 \%$ vs $18 \%(P=0.0007)$, cumulative incidence of molecular relapse $0 \%$ vs $27 \%(P<0.0001)$ but not OS $93 \%$ vs $89 \%(P=0.25)$. The incidence of death in remission was very low $2 \%$ vs $1 \%$ in both ATRA/ATO and AIDA cohorts, respectively. There was a trend toward significant improvement in the 4-year EFS for high-risk patients treated with ATRA/ATO vs AIDA ( $87 \%$ vs $64 \%$ ), but this did not reach significance $(P=0.07)$.

Table 2 provides a comparison of the most recent trials utilizing ATO in low-intermediate and high-risk APL.

\section{Arsenic side effects}

ATO can induce myelosuppression, hepatic dysfunction, gastrointestinal disturbance, hyperleukocytosis and DS. ${ }^{76,114,134,135,143}$ However, the most significant side effect requiring close monitoring is QT interval prolongation and the development of cardiac arrhythmia such as torsade de pointes. Electrocardiographic monitoring on a regular and frequent basis (twice weekly in our institution), measurement and replacement of electrolytes, especially potassium and magnesium, with the concurrent cessation of other drugs that can prolong the QT interval are recommended. Prolongation of the QT corrected for heart rate to $>500 \mathrm{~ms}$ should prompt cessation of ATO. Long-term rates of secondary malignancies have not been extensively studied, but one short medium-term study found no increase in the incidence of secondary neoplasms in patients treated with ATRA-ATO. ${ }^{144}$ Furthermore, no concerns regarding secondary malignancy were seen in long-term follow-up of a subset of the Shanghai cohort published recently. ${ }^{145}$

\section{Oral vs IV arsenic}

Oral formulations of ATO have been used to consolidate $\mathrm{CR}$ in newly diagnosed or relapsed adult and pediatric patients. ${ }^{146-149}$ Recent trials into the use of oral tetra-arsenic tetra-sulfide $\left(\mathrm{As}_{4} \mathrm{~S}_{4}\right)$ also known as Realgar, in a formulation with Indigo naturalis, Salvia miltiorrhiza and radix pseudostellariae (RIF), have shown apparent equivalency to intravenous ATO in the treatment of APL. APL07, a multicenter, randomized trial of 242 patients, found that in the primary outcome of 2-year DFS, ATRA-RIF induction was non-inferior to ATRA-ATO with subsequent common chemotherapy consolidation, $98.1 \%$ vs $95.5 \%$ (non-inferior $P<0.001)$. The $\mathrm{CR}$ rates were similar, $99.1 \%$ vs $97.2 \%$ $(P=0.62)$ and 3 -year OS of $99.1 \%$ vs $96.6 \%(P=0.18) .{ }^{150}$ On longer term follow-up of 231 patients, the 7-year CIR, EFS and OS rates in the RIF vs ATO cohorts were not significantly different, and there was no significant difference in the CIR, EFS or OS between the high-risk and non-highrisk group. ${ }^{151}$ Thus, Realgar-based therapy appears to be as efficacious as the ATO form. Researchers have proposed that while arsenic is known to target PML and induce its degradation via ubiquitination, ${ }^{114}$ the active agents in Indigo naturalis and S. miltiorrhiza (indirubin and tanshinone II, respectively) facilitate the uptake of arsenic into leukemic cells in a manner similar to ATRA. ${ }^{138,152}$ The ALLG APML5 trial (ACTRN12616001022459p) will soon begin recruiting to investigate the bioavailability and performance of a novel oral ATO formulation vs IV ATO in combination with ATRA in consolidation.

\section{The role of maintenance}

The relative contribution of maintenance therapy is controversial with evidence from the ATRA-chemotherapy era for and against its use. ${ }^{153-156}$ However, a recent Cochrane metaanalysis could not identify a benefit from maintenance for OS despite an improvement in DFS. ${ }^{157}$ Recent trials incorporating ATO have more clearly demonstrated the success achieved without maintenance in non-high-risk patients. The APL0406 trial demonstrated non-inferiority of ATRA-ATO without maintenance over ATRA-Ida with maintenance in non-highrisk patients..$^{39,142}$ In addition, non-high-risk patients treated 
Table 2 Results of recent ATO-inclusive trials

\begin{tabular}{|c|c|c|c|c|c|c|c|c|c|c|c|c|}
\hline $\begin{array}{l}\text { Risk } \\
\text { category }\end{array}$ & $\begin{array}{l}\text { Protocol } \\
\text { (published trial } \\
\text { analysis period) }\end{array}$ & $\begin{array}{l}\text { Median } \\
\text { follow-up } \\
\text { (years) }\end{array}$ & No & $\begin{array}{l}\text { Age } \\
\text { restriction } \\
\text { (years) }\end{array}$ & CR & ED & CIR & $\begin{array}{l}\text { Death } \\
\text { in } \mathbf{C R}\end{array}$ & DFS & EFS & os & $\begin{array}{l}\text { Therapy-related } \\
\text { neoplasm }\end{array}$ \\
\hline Low-intermediate & APL0406 ${ }^{142}$ & 3.4 & 127 & $|8-7|$ & $100 \%$ & $0 \%$ & $1.9 \%$ & $0.8 \%$ & ns & $97.3 \%$ & $99.2 \%$ & 0 \\
\hline \multirow[t]{20}{*}{ risk } & $\begin{array}{l}\text { ATRA-ATO } \\
(4-y r)\end{array}$ & & & & & & & & & & & \\
\hline & APL0406 & 3.4 & 132 & $|8-7|$ & $97 \%$ & $3 \%$ & $13.9 \%$ & $3.7 \%$ & ns & $80 \%$ & $92.6 \%$ & 2 \\
\hline & $\begin{array}{l}\text { ATRA-Ida } \\
(4-y r)\end{array}$ & & & & & & & & & & & \\
\hline & UK AMLI $7^{40}$ & 2.5 & 86 & $\geq 16$ & $94 \%$ & $4 \%$ & $1 \%^{\mathrm{a}, \mathrm{c}}$ & $2 \%^{c}$ & $97 \%^{\mathrm{a}}$ & $92 \%$ & $95 \%^{d}$ & 0 \\
\hline & $\begin{array}{l}\text { ATRA-ATO } \pm \text { GO } \\
(4-y r)\end{array}$ & & & & $\begin{array}{l}\text { (all risk } \\
\text { groups) }\end{array}$ & & $0 \%$ b,c & & $98 \%{ }^{\mathrm{b}}$ & & & \\
\hline & UK-AMLI7 & 2.5 & 92 & $\geq 16$ & $89 \%$ & $6 \%$ & $18 \%^{\mathrm{a}}$ & $1 \% c$ & $78 \%^{\mathrm{a}}$ & $71 \%$ & $90 \%{ }^{c}$ & I-risk group ns \\
\hline & $\begin{array}{l}\text { ATRA-Ida } \\
(4-y r)\end{array}$ & & & & $\begin{array}{l}\text { (all risk } \\
\text { groups) }\end{array}$ & & $27 \%$ b & & $70 \%$ & & & \\
\hline & MD Anderson ${ }^{139}$ & 1.9 & 56 & ns & $95 \%$ & $3.6 \%$ & $0 \%$ & $4 \%$ & ns & $89 \%$ & $89 \%$ & ns \\
\hline & $\begin{array}{l}\text { ATRA/ATO } \pm \text { GO } \\
(3-y r)\end{array}$ & & & & & & & $\begin{array}{l}\text { of all } \\
\text { patients }\end{array}$ & & & & \\
\hline & $\begin{array}{l}\text { North American } \\
\text { Intergroup }\end{array}$ & 2.4 & 144 & $\geq 15$ & $93 \%-94 \%$ & $4 \%$ & ns & ns & $77 \%{ }^{\mathrm{e}}$ & $71 \%$ & ns & ns \\
\hline & $\mathrm{C} 9710^{36}$ & & & & & & & & & & & \\
\hline & No ATO in & & & & & & & & & & & \\
\hline & $\begin{array}{l}\text { Consolidation } \\
(3-y r)\end{array}$ & & & & & & & & & & & \\
\hline & North American & 2.4 & 189 & $\geq 15$ & $93 \%-94 \%$ & $4 \%$ & ns & ns & $90 \%{ }^{\mathrm{e}}$ & $84 \%{ }^{\mathrm{e}}$ & ns & ns \\
\hline & Intergroup & & & & & & & & & & & \\
\hline & C97IO & & & & & & & & & & & \\
\hline & ATO in & & & & & & & & & & & \\
\hline & $\begin{array}{l}\text { consolidation } \\
(3-y r)\end{array}$ & & & & & & & & & & & \\
\hline & APML4 $^{41}$ & 4.2 & 101 & $>1$ & $96 \%$ & $2 \%$ & $5 \%$ & $0 \%$ & $96 \%$ & $92 \%$ & $96 \%$ & ns \\
\hline & $\begin{array}{l}\text { ATRA-ATO-Ida } \\
(5-y r)\end{array}$ & & & & & & & & & & & \\
\hline \multirow[t]{18}{*}{ High-risk } & UK AMLI $7^{40}$ & 2.5 & 30 & $\geq 16$ & ns & ns & ns & $2 \%$ c & ns & $87 \%^{f}$ & $87 \%^{d}$ & ns \\
\hline & $\begin{array}{l}\text { ATRA-ATO } \\
(4-y r)\end{array}$ & & & & & & & & & & & \\
\hline & UK AMLI 7 & 2.5 & 27 & $\geq 16$ & ns & ns & ns & $1 \% c$ & ns & $64 \%^{f}$ & $84 \%^{d}$ & ns \\
\hline & $\begin{array}{l}\text { ATRA-Ida } \\
(4-y r)\end{array}$ & & & & & & & & & & & \\
\hline & MD Anderson 139 & 1.9 & 26 & ns & $81 \%$ & $19 \%$ & $11 \%$ & $4 \%$ & ns & $65 \%{ }^{\mathrm{e}}$ & $75 \%$ & ns \\
\hline & $\begin{array}{l}\text { ATRA/ATO } \pm \mathrm{GO} \\
(3-y r)\end{array}$ & & & & & & & $\begin{array}{l}\text { of all } \\
\text { patients }\end{array}$ & & & & \\
\hline & North American & 2.4 & 58 & $\geq 15$ & $71 \%$ & $20 \%$ & ns & ns & $46 \%{ }^{\mathrm{e}}$ & $39 \%$ & ns & ns \\
\hline & Intergroup & & & & & & & & & & & \\
\hline & C971 $0^{36}$ & & & & & & & & & & & \\
\hline & No ATO & & & & & & & & & & & \\
\hline & $(3-y r)$ & & & & & & & & & & & \\
\hline & North American & 2.4 & 55 & $\geq 15$ & $71 \%$ & $20 \%$ & ns & ns & $87 \%$ & $64 \%$ & ns & ns \\
\hline & Intergroup & & & & & & & & & & & \\
\hline & C97IO & & & & & & & & & & & \\
\hline & ATO & & & & & & & & & & & \\
\hline & $\begin{array}{l}\text { consolidation } \\
(3-y r)\end{array}$ & & & & & & & & & & & \\
\hline & APML4 ${ }^{41}$ & 4.2 & 23 & $>1$ & $88 \%$ & $8.7 \%$ & $5 \%$ & $0 \%$ & $95 \%$ & $83 \%$ & $87 \%$ & ns \\
\hline & $\begin{array}{l}\text { ATRA-ATO-Ida } \\
(5-y r)\end{array}$ & & & & & & & & & & & \\
\hline
\end{tabular}

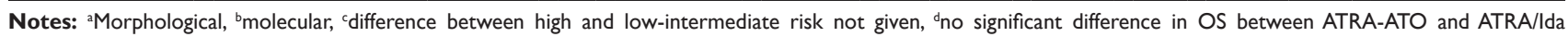
therapy within risk groups, estimated from published survival curves (data not given), 'no significant difference in EFS between ATRA-ATO and ATRA/lda in high-risk patients. The year given in parentheses is the time-point at which the survival endpoints were analyzed.

Abbreviations: ATO, arsenic trioxide; CR, complete remission; CIR, cumulative incidence of relapse; DFS, disease-free survival; ED, early death; EFS, event-free survival; OS, overall survival; ATRA, all trans-retinoic acid; ns, not specified; Ida, idarubicin; GO, gemtuzumab ozogamicin. 
with ATRA-ATO in the UK AML17 trial achieved a 4-year OS of $95 \%$ with an overall 4-year cumulative incidence of morphological relapse of $1 \%$ in the ATRA-ATO arm despite no maintenance therapy. ${ }^{40}$ In the APML4 trial, ${ }^{38,41}$ the lack of significant difference in the freedom from relapse between high- and non-high-risk patients appears to be the result of the ATRA-ATO-Ida induction and prolonged ATRA-ATO consolidation, not a historical maintenance regimen. In the era of oral ATRA-arsenic therapy, it may be that prolonged oral consolidation or maintenance therapy will prove useful in high-risk patients in combination with less chemotherapy intensive regimens.

\section{FLT3 mutation}

Mutations within FLT3, either ITDs or tyrosine kinase domain mutations, are present in $12 \%-38 \%$ and $2 \%-20 \%$ of cases of APL, respectively. ${ }^{158,159}$

The effects of FLT3 mutations on patient outcomes are inconsistent and appear dependent on the treatment regimen..$^{38,91,132,159-161}$ A meta-analysis by Beitinjaneh et al of patients treated predominantly with ATRA and chemotherapy identified lower rates of DFS and OS in patients with a FLT3-ITD. The risk ratio for 3-year DFS and OS in FLT3-ITD compared to wild type was $1.477, P=0.042$ and $1.42, P=0.03$, respectively. ${ }^{159}$ Possession of a FLT3 mutation also appeared to increase the risk of induction death in adults and children. ${ }^{158,162}$ The addition of ATO to therapy appears to overcome the deleterious impact of a FLT3 mutation. The negative effect of FLT3 mutation on OS found in the ALLG APML3 trial was absent after the addition of ATO in induction and consolidation in the follow-up APML4 trial. ${ }^{38,91}$ Similarly, in the APL0406 trial cohort of low-intermediate risk patients, the presence of a FLT3 mutation was not associated with a poorer EFS when treated with ATO/ATRA. However, there was a trend toward a poorer EFS when treated without ATO in combination with ATRA. ${ }^{163}$

In addition to FLT3 mutations, other pretreatment parameters associated with inferior prognosis include short PML-RARA isoforms (associated with bcr3 breakpoints) and increased expression of CD2, CD34 and CD56. ${ }^{164}$ However, their relevance in the era of arsenic-based therapy has not been confirmed.

\section{Early deaths}

The unparalleled rates of survival in patients achieving a CR through current treatment protocols only help to highlight the continuing problem of early deaths. In contemporary trial publications from tertiary centers, the early death rates are $<10 \%{ }^{36,37,93,132,165}$ However, this is likely to underestimate the true rate as the trial data are vulnerable to various forms of selection bias, eg, failure to include diagnosed patients who succumb prior to therapy, restriction according to age or performance status or those who were never appropriately diagnosed in the first instance. ${ }^{93,166,167}$ Retrospective analysis of patient outcomes outside the confines of a trial and population data identifies the rate of early death as between $17 \%$ and $29 \%$. $^{8,165,167-169}$

Coagulopathy and catastrophic bleeding, particularly within the brain and lungs, are the most common causes of early demise..$^{8,167,169-171}$ There is a pathological activation of both pro-coagulant and fibrinolytic pathways in APL, and the contributions of tissue factor (TF), cancer procoagulant, Annexin II, plasminogen and thrombin activatable fibrinolytic inhibitor (TAFI) have been reviewed by both Breen et al ${ }^{172}$ and Kwaan and Cull. ${ }^{173}$ The pathological disturbance in the fibrinolytic pathway largely driven by increased Annexin II expression on abnormal promyelocytes is reversed by ATRA-induced differentiation. ${ }^{174}$ However, pro-apoptotic treatment with chemotherapy and/or ATO will increase the levels of pro-coagulants, such as TF and cellular/membrane phospholipids. Therefore, treatment with ATRA should be started at the earliest suspicion of APL after clinical and morphological assessment, while awaiting confirmatory molecular or cytogenetic testing, and should be combined with aggressive hemostatic support programs using platelets and appropriate plasma components. ${ }^{78}$ Recent reports detailed the use of a recombinant form of the thrombin inhibitor, thrombomodulin, in the treatment of APL-associated coagulopathy. ${ }^{175-177}$ The thrombin-thrombomodulin complex in association with plasmin activates TAFI, and thereby inhibits fibrinolysis. ${ }^{178}$

The simplest and most powerful intervention shown to reduce the early death rate is education to both improve early identification of patients with APL and advocate for urgent initiation of therapy in a manner analogous to the emphasis on timely treatment of patients with acute coronary syndromes. Programs in developing countries to improve the treatment of patients using education, international collaboration, support and specific committees tasked with improving drug access and early initiation have driven dramatic improvements in patient survival. ${ }^{179}$

\section{Pediatric patients}

There is an increased incidence of the microgranular variant (M3v) of APL in children, with associated leukocytosis and greater risk of coagulopathy and/or DS. ${ }^{180}$ The treatment of children with APL has mirrored the developments made in 
adult therapy, and currently accepted protocols are based on research by the APL, GIMEMA, PETHEMA and GermanAustrian-Swiss groups. Combinations of ATRA and chemotherapy help to achieve CR and 5-year OS rates between $92 \%-95 \%$ and $87 \%-90 \%$, respectively. ${ }^{181-185}$ Protocol modifications in the pediatric population include the reduction of ATRA dose to $25 \mathrm{mg} / \mathrm{m}^{2}$, which helps to reduce the severity of side effects including headaches and pseudotumor cerebri, while achieving similar results to $45 \mathrm{mg} / \mathrm{m}^{2}{ }^{78,184-187}$ Independent studies by German and Japanese investigators using ATRA throughout induction, consolidation and maintenance and utilizing anthracycline and high-dose cytarabine in consolidation have shown similar OS rates. Creutzig et $\mathrm{al}^{188}$ reported an OS of $89 \%$ at 5 years for pediatric patients in consecutive AML-Berlin/Frankfurt/Muenster trials.
Imaizumi et $\mathrm{al}^{189}$ reported that patients in the AML99-M3 study achieved an OS of $91 \%$ at 7 years.

ATO used as monotherapy for induction, consolidation and maintenance treatment of 11 children with microgranular APL in Vellore induced a CR in 91\% with 30-month OS of $91 \%$ and RFS of $81 \% .{ }^{190}$ Similarly, researchers in China treated 19 children (including seven high-risk patients) with single-agent ATO for induction of remission and 3 years postremission therapy. The CR, 5-year OS and EFS rates were $89.5 \%, 83.9 \%$ and $72.7 \%$, respectively. ${ }^{191}$ Another singlecenter analysis compared ATRA vs ATRA-ATO induction with the use of ATRA in consolidation for all children and an additional 28-day cycle of ATO in consolidation for the experimental arm. All children also received extensive consolidation chemotherapy. There was a significant

Table 3 Commonly employed current treatment regimens in APL, stratified by risk category

\begin{tabular}{|c|c|c|c|}
\hline Protocol & Induction & Consolidation & Maintenance \\
\hline \multicolumn{4}{|c|}{ Low-intermediate risk } \\
\hline APL0406 ${ }^{39}$ & $\begin{array}{l}\text { ATRA } 45 \mathrm{mg} / \mathrm{m}^{2} / \mathrm{d} \text { PO + } \\
\text { ATO } 0.15 \mathrm{mg} / \mathrm{kg} / \mathrm{d} \text { IV until CR } \\
(\max 60 \text { days) }\end{array}$ & $\begin{array}{l}\text { ATRA } 45 \mathrm{mg} / \mathrm{m}^{2} / \mathrm{d} \text { PO for } 14 \text { days then rest for } \\
\text { I } 4 \text { days } \times 7 \text { cycles }+ \text { ATO } 0.15 \mathrm{mg} / \mathrm{kg} / \mathrm{d} \text { IV for } \\
5 \text { days per week for } 4 \text { weeks then rest for } \\
4 \text { weeks } \times 4 \text { cycles }\end{array}$ & $\mathrm{Nil}$ \\
\hline LPA2005 ${ }^{37}$ & $\begin{array}{l}\text { ATRA } 45 \mathrm{mg} / \mathrm{m}^{2} / \mathrm{d} \mathrm{PO}^{c}+ \\
\text { ATO } 0.15 \mathrm{mg} / \mathrm{kg} / \mathrm{d} \text { IV until CR } \\
(\max 60 \text { days) }\end{array}$ & $\begin{array}{l}\text { I. ATRA } 45 \mathrm{mg} / \mathrm{m}^{2} / \mathrm{d} \text { PO dI- } 15+ \\
\text { Idarubicin } 5^{\text {low }} / 7^{\text {int }} \mathrm{mg} / \mathrm{m}^{2} / \mathrm{d} \mathrm{dl}-4 \\
\text { 2. ATRA } 45 \mathrm{mg} / \mathrm{m}^{2} / \mathrm{d} \text { PO dI- } 15+ \\
\text { MTZ } 10 \mathrm{mg} / \mathrm{m}^{2} / \mathrm{d} \mathrm{dl}-3 \\
\text { 3. ATRA } 45 \mathrm{mg} / \mathrm{m}^{2} / \mathrm{d} \text { PO dI- } 15+ \\
\text { Idarubicin } 12 \mathrm{mg} / \mathrm{m}^{2} / \mathrm{d} \text { dl low or } \mathrm{dl}-2^{\text {int }}\end{array}$ & $\begin{array}{l}\text { ATRA } 45 \mathrm{mg} / \mathrm{m}^{2} / \text { day PO dI-I5 } \\
\text { every } 90 \text { days } \\
\text { MTX } 15 \mathrm{mg} / \mathrm{m}^{2} / \mathrm{wk} \text { IM dI } 5-90 \\
\text { 6-MP } 50 \mathrm{mg} / \mathrm{m}^{2} / \mathrm{wk} \text { PO dI5-90 } \\
\text { for } 2 \text { years }\end{array}$ \\
\hline \multicolumn{4}{|l|}{ High risk } \\
\hline APML4 ${ }^{38}$ & $\begin{array}{l}\text { ATRA } 45 \mathrm{mg} / \mathrm{m}^{2} / \text { day PO dI-36 } \\
\text { ATO } 0.15 \mathrm{mg} / \mathrm{kg} / \text { day IV d9-36 } \\
\text { Idarubicin } 6-12 \mathrm{mg} / \mathrm{m}^{2} \\
\mathrm{~d} 2,4,6,8^{\mathrm{a}, \mathrm{b}}\end{array}$ & $\begin{array}{l}\text { I. ATRA } 45 \mathrm{mg} / \mathrm{m}^{2} / \mathrm{d} \text { PO days I-28 + } \\
\text { ATO } 0.15 \mathrm{mg} / \mathrm{kg} / \mathrm{d} \text { IV dI-28 } \\
\text { 2. ATRA } 45 \mathrm{mg} / \mathrm{m}^{2} / \mathrm{d} \text { PO dI-7, I5-2I } \\
\text { and } 29-35+\text { ATO } 0.15 \mathrm{mg} / \mathrm{kg} / \mathrm{d} \text { IV for } \\
5 \text { days per week for } 5 \text { weeks }\end{array}$ & $\begin{array}{l}\text { ATRA } 45 \mathrm{mg} / \mathrm{m}^{2} / \text { day } \\
\text { PO dI- } 14 \text { every } 90 \text { days } \\
\text { MTX } 5-15 \mathrm{mg} / \mathrm{m}^{2} / \mathrm{wk} \text { PO dI } 5-90 \\
6 \text {-MP } 50-90 \mathrm{mg} / \mathrm{m}^{2} / \mathrm{wk} \text { PO dI5-90 } \\
\times 8 \text { cycles }\end{array}$ \\
\hline $\begin{array}{l}\text { Study } \\
\text { C97 } 10^{36}\end{array}$ & $\begin{array}{l}\text { ATRA } 45 \mathrm{mg} / \mathrm{m}^{2} / \mathrm{d} \text { PO until CR } \\
(\max 90 \mathrm{days})+\text { Cytarabine } \\
200 \mathrm{mg} / \mathrm{m}^{2} \mathrm{~d} 3-9+ \\
\text { DNR } 50 \mathrm{mg} / \mathrm{m}^{2} \mathrm{~d} 3-6\end{array}$ & $\begin{array}{l}\text { I. ATO } 0.15 \mathrm{mg} / \mathrm{kg} / \mathrm{d} \text { IV for } 5 \text { days per week } \\
\text { for } 5 \text { weeks } \times 2 \text { cycles } \\
\text { 2. ATRA } \mathrm{mg} / \mathrm{m}^{2} / \mathrm{d} \text { PO days I-7 + DNR } \\
50 \mathrm{mg} / \mathrm{m}^{2} \mathrm{dl}-3 \times 2 \text { cycles }\end{array}$ & $\begin{array}{l}\text { ATRA } \mathrm{mg} / \mathrm{m}^{2} / \mathrm{d} \text { PO days I-7 } \\
\text { repeated on alternate weeks } \\
\text { MTX } 20 \mathrm{mg} / \mathrm{m}^{2} / \mathrm{wk} \text { PO } \\
6-\mathrm{MP} 60 \mathrm{mg} / \mathrm{m}^{2} / \mathrm{d} \text { PO for I year }\end{array}$ \\
\hline APL2000\% & $\begin{array}{l}\text { ATRA } 45 \mathrm{mg} / \mathrm{m}^{2} / \mathrm{d} \text { PO until } \\
\text { CR + Cytarabine } 200 \mathrm{mg} / \mathrm{m}^{2} \\
\mathrm{dl}-7+\text { DNR } 60 \mathrm{mg} / \mathrm{m}^{2} \mathrm{dl}-3\end{array}$ & $\begin{array}{l}\text { I. DNR } 60 \mathrm{mg} / \mathrm{m}^{2} / \mathrm{d} \mathrm{dl}-3+\text { Cytarabine } \\
200 \mathrm{mg} / \mathrm{m}^{2} / \mathrm{d} \mathrm{dl}-7 \\
\text { 2. DNR } 45 \mathrm{mg} / \mathrm{m}^{2} / \mathrm{d} \mathrm{dl}-3+\text { Cytarabine } \\
2 \mathrm{~g} / \mathrm{m}^{2} / \mathrm{I} 2 \mathrm{~h} \mathrm{dl}-5 \text { (50 years) or Cytarabine } \\
\text { I.5 g/m } / \mathrm{m}^{2} / \mathrm{I} 2 \mathrm{~h} \mathrm{dl}-5 \text { (50-60 years) + } 5 \text { doses } \\
\text { of } \mathrm{MTX} \mathrm{I} 5 \mathrm{mg} / \text { Cytarabine } 50 \mathrm{mg} \text { given IT }\end{array}$ & $\begin{array}{l}\text { ATRA } 45 \mathrm{mg} / \mathrm{m}^{2} / \text { day PO } \\
\text { dI- } 15 \text { every } 90 \text { days } \\
\text { MTX } 15 \mathrm{mg} / \mathrm{m}^{2} / \mathrm{wk} \text { PO dI } 5-90 \\
\text { 6-MP } 50 \mathrm{mg} / \mathrm{m}^{2} / \mathrm{wk} \text { PO dl } 5-90 \\
\text { for } 2 \text { years }\end{array}$ \\
\hline LPA2005 ${ }^{37}$ & $\begin{array}{l}\text { ATRA } 45 \mathrm{mg} / \mathrm{m}^{2} / \mathrm{d} \mathrm{PO}^{\mathrm{c}} \text { until } \\
\text { CR + Idarubicin } 12 \mathrm{mg} / \mathrm{m}^{2} / \mathrm{d} \\
\mathrm{d} 2,4,6,8^{\mathrm{d}}\end{array}$ & $\begin{array}{l}\text { I. ATRA } 45 \mathrm{mg} / \mathrm{m}^{2} / \mathrm{d} \text { PO dl-I5 + Idarubicin } \\
5 \mathrm{mg} / \mathrm{m}^{2} / \mathrm{d} \mathrm{dl}-4+\text { Cytarabine I g/m²/d dl-4 } \\
\text { 2. ATRA } 45 \mathrm{mg} / \mathrm{m}^{2} / \mathrm{d} \text { PO + MTZ } 10 \mathrm{mg} / \mathrm{m}^{2} / \mathrm{d} \\
\text { dI-5 } \\
\text { 3. ATRA } 45 \mathrm{mg} / \mathrm{m}^{2} / \mathrm{d} \text { PO + Idarubicin } 12 \mathrm{mg} / \mathrm{m}^{2} / \mathrm{d} \\
\text { dI }+ \text { Cytarabine } 150 \mathrm{mg} / \mathrm{m}^{2} / 8 \mathrm{~h} \mathrm{dI-4}\end{array}$ & $\begin{array}{l}\text { ATRA } 45 \mathrm{mg} / \mathrm{m}^{2} / \text { day PO } \\
\text { dI-I } 5 \text { every } 90 \text { days } \\
\text { MTX } 15 \mathrm{mg} / \mathrm{m}^{2} / \mathrm{wk} \text { IM dI } 5-90 \\
6 \text {-MP } 50 \mathrm{mg} / \mathrm{m}^{2} / \mathrm{wk} \text { PO d } 5-90 \\
\text { for } 2 \text { years }\end{array}$ \\
\hline
\end{tabular}

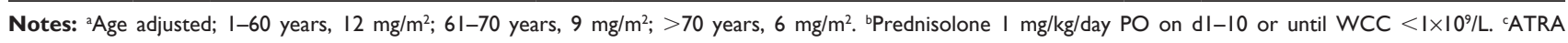
$25 \mathrm{mg} / \mathrm{m}^{2} / \mathrm{d}$ if $\leq 20$ years. Ilf $>70$ years Idarubicin $12 \mathrm{mg} / \mathrm{m}^{2} \mathrm{~d} 8$ omitted. elf $>60$ years no Cytarabine given in consolidation and Idarubicin dose as per intermediate risk patients described in LPA2005 low-int risk protocol.

Abbreviations: Low, low risk patients; Int, intermediate risk patients; MTX, Methotrexate; 6-MP, Mercaptopurine; DNR, Daunorubicin; MTZ, Mitoxantrone; IT, intrathecal; IM, intramuscular; IV, intravenous; PO, per os (orally). 
improvement in survival with the inclusion of ATO with a 6.25-year EFS, DFS and OS for ATRA vs ATRA-ATO of $70.4 \%$ vs $92.5 \%(P=0.021), 76.4 \%$ vs $97.1 \%(P=0.012)$ and $70.4 \%$ vs $95.3 \%(P=0.007)$, respectively. ${ }^{192}$

Therefore, progress has been made toward the introduction of ATRA-arsenic in the pediatric population, but risk-adapted trials to investigate rationalized chemotherapy are lacking. The Children's Oncology Group Phase III, multicenter AAML0631 and AAML1331 trials (NCT00866918 and NCT02339740) are currently underway and aim to investigate risk-adapted and arsenic-based strategies in children.

\section{Pregnancy}

The management of pregnant patients with APL has been discussed in the European LeukemiaNet recommendations and most recently and succinctly by Milojkovic and Apperley. ${ }^{78,193}$ In summary, the management of APL in the first trimester rests on the decision on whether an elective termination is chosen as this will allow the initiation of standard ATRA-chemotherapy or ATRA-ATO-based therapy that is otherwise contraindicated. Should the patient elect to continue the pregnancy, then ATRA is excluded in the first trimester because of the risk of fetal malformations. ${ }^{193}$ Arsenic therapy is not possible at any time in pregnancy due to its embryotoxicity. ${ }^{194,195}$ Treatment with daunorubicin is recommended, given its lower capacity to transfer across the placenta, lower solubility in lipids compared to idarubicin and shorter half-life. However, there remains an increased risk of abortion, premature labor, neonatal neutropenia and low birth weight. ${ }^{194}$ Treatment after the second trimester can include the use of ATRA in combination with daunorubicin or as monotherapy, although there is an associated risk of ATRA resistance, short remission and DS in newly diagnosed patients. ${ }^{71-73,196}$ Similarly, treatment with daunorubicin alone in newly diagnosed patients carries the risk of the exacerbation of the APL-associated coagulopathy and hemorrhage. Combination daunorubicin-ATRA therapy would logically achieve the best outcomes for the patient (and indirectly the fetus) but close monitoring of the potentially toxic side effects is essential including cardiac toxicity associated with ATRA. ${ }^{78,197,198}$ In all patients, there is a need for comprehensive multi-disciplinary care involving an obstetrician, a fetal medicine specialist and a hematologist.

\section{Conclusion}

The paradigm of differentiation therapy constructed on the discovery and success with ATRA has evolved with the introduction of ATO and the recognition of the synergistic destruction of the PML-RARA protein. The serendipitous discovery of two agents that directly target the $P M L-R A R A$ mutation that drives disease has led to unparalleled success in patient cure, through better eradication of LICs. The benefits of risk-adapted therapy with ATRA-chemotherapy and now ATRA-ATO without chemotherapy have been established for low-intermediate risk patients. Recent research appears to show that in high-risk patients, ATRA-ATO may overcome the increased relapse risk provided they are combined with rationally reduced use of chemotherapy or gemtuzumab ozogamicin, and randomized controlled trials are underway that will hopefully confirm this. Maintenance therapy appears dispensable in low-risk patients treated with ATRA-ATO, but this has not been defined in the high-risk cohort. There is significant progress to be made in the early death rate, particularly in developing countries, and the increasing availability of oral ATRA therapy may facilitate this. Examples of currently recommended treatment regimens for APL are summarized in Table 3.

\section{Disclosure}

The authors report no conflicts of interest in this work.

\section{References}

1. Hillestad LK. Acute promyelocytic leukemia. Acta Med Scand. 1957; 159(3):189-194.

2. Pisciotta AV, Schulz EJ. Fibrinolytic purpura in acute leukemia. Am J Med. 1955;19(5):824-828.

3. Cooperberg AA, Neiman GMA. Fibrinogenopenia and fibrinolysis in acute myelogenous leukemia. Ann Intern Med. 1955;42(3):706-711.

4. Croizat P, Favre-Gilly J. Les aspects du syndrome hémorragique des leucémies; à propos de 12 cas de thrombocytopénie et d'un cas de fibrinopénie [Aspects of the leukemia hemorrhagic syndrome; in 12 cases of thrombocytopenia and one case of fibrinopenia]. Sang. 1949;20(7):417-421. French.

5. Rizak E. Die Fibrinopenie [The Fibrinopenia]. Z Klin Med. 1935;128: 605. German.

6. Bernard J, Mathe G, Boulay J, Ceoard B, Chome J. La leucemie aiguë à promyelocytes. Étude portant sur vingt observations [Acute promyelocytic leukemia: a study made on 20 cases]. Schweiz Med Wochenschr. 1959;89:604-608. French.

7. Grimwade D, Hills RK, Moorman AV, et al; National Cancer Research Institute Adult Leukaemia Working Group. Refinement of cytogenetic classification in acute myeloid leukemia: determination of prognostic significance of rare recurring chromosomal abnormalities among 5876 younger adult patients treated in the United Kingdom Medical Research Council trials. Blood. 2010;116(3):354-365.

8. Lehmann S, Ravn A, Carlsson L, et al. Continuing high early death rate in acute promyelocytic leukemia: a population-based report from the Swedish Adult Acute Leukemia Registry. Leukemia. 2011;25(7): 1128-1134.

9. Rego EM, Jácomo RH. Epidemiology and treatment of acute promyelocytic leukemia in Latin America. Mediterr J Hematol Infect Dis. 2011;3(1): e2011049.

10. Douer D. The epidemiology of acute promyelocytic leukaemia. Best Prac Res Clin Haematol. 2003;16(3):357-367.

11. Bennett JM, Catovsky D, Daniel M-T, et al. Proposals for the classification of the acute leukaemias French-American-British (FAB) Co-operative Group. Br J Haematol. 1976;33(4):451-458. 
12. Bennett JM, Catovsky D, Daniel MT, et al. A variant form of hypergranular promyelocytic leukaemia (M3). Br J Haematol. 1980;44(1): 169-170.

13. Rowley JD, Golomb HM, Dougherty C. 15/17 translocation, a consistent chromosomal change in acute promyelocytic leukaemia. Lancet. 1977; 1(8010):549-550.

14. Testa J, Golomb H, Rowley J, Vardiman J, Sweet DJ. Hypergranular promyelocytic leukemia (APL): cytogenetic and ultrastructural specificity. Blood. 1978;52(2):272-280.

15. Swerdlow SHCE, Harris NL, Jaffe ES, et al. WHO Classification of Tumours of Haematopoietic and Lymphoid Tissue. Lyon: The International Agency for Research on Cancer; 2008.

16. Arber DA, Orazi A, Hasserjian R, et al. The 2016 revision to the World Health Organization (WHO) classification of myeloid neoplasms and acute leukemia. Blood. 2016;127(20):2391-2405.

17. Madan V, Shyamsunder P, Han L, et al. Comprehensive mutational analysis of primary and relapse acute promyelocytic leukemia. Leukemia. 2016;30:1672-1681.

18. NCI (NIH) [webpage on the Internet]. SEER Stat Fact Sheets: Acute Myeloid Leukemia (AML). NIH (online) 2016. Available from: http://seer. cancer.gov/statfacts/html/amyl.html. Accessed November 3, 2016.

19. Appelbaum FR, Gundacker H, Head DR, et al. Age and acute myeloid leukemia. Blood. 2006;107(9):3481-3485.

20. Pulte D, Gondos A, Brenner H. Improvements in survival of adults diagnosed with acute myeloblastic leukemia in the early 21 st century. Haematologica. 2008;93(4):594-600.

21. Döhner H, Weisdorf DJ, Bloomfield CD. Acute myeloid leukemia. N Engl J Med. 2015;373:1136-1152.

22. Grimwade D, Walker H, Oliver F, et al. The importance of diagnostic cytogenetics on outcome in AML: analysis of 1,612 patients entered into the MRC AML 10 trial. Blood. 1998;92:2322-2333.

23. Slovak ML, Kopecky KJ, Cassileth PA, et al. Karyotypic analysis predicts outcome of preremission and postremission therapy in adult acute myeloid leukemia: a Southwest Oncology Group/Eastern Cooperative Oncology Group study. Blood. 2000;96(13):4075-4083.

24. Byrd JC, Mrozek K, Dodge RK, et al; Cancer and Leukemia Group B (CALGB 8461). Pretreatment cytogenetic abnormalities are predictive of induction success, cumulative incidence of relapse, and overall survival in adult patients with de novo acute myeloid leukemia: results from Cancer and Leukemia Group B (CALGB 8461). Blood. 2002;100(13):4325-4336.

25. Schnittger S, Schoch C, Kern W, et al. Nucleophosmin gene mutations are predictors of favorable prognosis in acute myelogenous leukemia with a normal karyotype. Blood. 2005;106(12):3733-3739.

26. Thiede C, Koch S, Creutzig E, et al. Prevalence and prognostic impact of NPM1 mutations in 1485 adult patients with acute myeloid leukemia (AML). Blood. 2006;107(10):4011-4020.

27. Mrózek K, Marcucci G, Paschka P, Whitman SP, Bloomfield CD. Clinical relevance of mutations and gene-expression changes in adult acute myeloid leukemia with normal cytogenetics: are we ready for a prognostically prioritized molecular classification? Blood. 2007;109(2):431-448.

28. Schlenk RF, Döhner K, Krauter J, et al; German-Austrian Acute Myeloid Leukemia Study Group. Mutations and treatment outcome in cytogenetically normal acute myeloid leukemia. N Engl J Med. 2008; 358(18):1909-1918.

29. Hou HA, Lin LI, Chen CY, Tien HF. Reply to 'Heterogeneity within AML with CEBPA mutations; only CEBPA double mutations, but not single CEBPA mutations are associated with favorable prognosis'. Br J Cancer. 2009;101(4):738-740.

30. Pabst T, Eyholzer M, Fos J, Mueller BU. Heterogeneity within AML with CEBPA mutations; only CEBPA double mutations, but not single CEBPA mutations are associated with favourable prognosis. $\mathrm{Br} \mathrm{J}$ Cancer. 2009;100(8):1343-1346.

31. Wouters BJ, Löwenberg B, Erpelinck-Verschueren CAJ, van Putten WLJ, Valk PJM, Delwel R. Double CEBPA mutations, but not single CEBPA mutations, define a subgroup of acute myeloid leukemia with a distinctive gene expression profile that is uniquely associated with a favorable outcome. Blood. 2009;113:3088-3091.
32. Dufour A, Schneider F, Metzeler KH, et al. Acute myeloid leukemia with biallelic CEBPA gene mutations and normal karyotype represents a distinct genetic entity associated with a favorable clinical outcome. J Clin Oncol. 2010;28(4):570-577.

33. Green CL, Koo KK, Hills RK, Burnett AK, Linch DC, Gale RE. Prognostic significance of CEBPA mutations in a large cohort of younger adult patients with acute myeloid leukemia: impact of double CEBPA mutations and the interaction with FLT3 and NPM1 mutations. J Clin Oncol. 2010;28(16):2739-2747.

34. Taskesen E, Bullinger L, Corbacioglu A, et al. Prognostic impact, concurrent genetic mutations, and gene expression features of AML with CEBPA mutations in a cohort of 1182 cytogenetically normal AML patients: further evidence for CEBPA double mutant AML as a distinctive disease entity. Blood. 2011;117(8):2469-2475.

35. Estey E, Garcia-Manero G, Ferrajoli A, et al. Use of all-trans retinoic acid plus arsenic trioxide as an alternative to chemotherapy in untreated acute promyelocytic leukemia. Blood. 2006;107(9):3469-3473.

36. Powell BL, Moser B, Stock W, et al. Arsenic trioxide improves eventfree and overall survival for adults with acute promyelocytic leukemia: North American Leukemia Intergroup Study C9710. Blood. 2010; 116(19):3751-3757.

37. Sanz MA, Montesinos P, Rayon C, et al; PETHEMA and HOVON Groups. Risk-adapted treatment of acute promyelocytic leukemia based on all-trans retinoic acid and anthracycline with addition of cytarabine in consolidation therapy for high-risk patients: further improvements in treatment outcome. Blood. 2010;115(25):5137-5146.

38. Iland HJ, Bradstock K, Supple SG, et al; Australasian Leukaemia and Lymphoma Group. All-trans-retinoic acid, idarubicin, and IV arsenic trioxide as initial therapy in acute promyelocytic leukemia (APML4). Blood. 2012;120(8):1570-1580.

39. Lo-Coco F, Avvisati G, Vignetti M, et al; Gruppo Italiano Malattie Ematologiche dell'Adulto, the German-Austrian Acute Myeloid Leukemia Study Group, and Study Alliance Leukemia. Retinoic acid and arsenic trioxide for acute promyelocytic leukemia. $N$ Engl J Med. 2013;369(2): 111-121.

40. Burnett AK, Russell NH, Hills RK, et al; the UK National Cancer Research Institute Acute Myeloid Leukaemia Working Group. Arsenic trioxide and all-trans retinoic acid treatment for acute promyelocytic leukaemia in all risk groups (AML17): results of a randomised, controlled, phase 3 trial. Lancet Oncol. 2015;16(13):1295-1305.

41. Iland HJ, Collins M, Bradstock K, et al; Australasian Leukaemia and Lymphoma Group. Use of arsenic trioxide in remission induction and consolidation therapy for acute promyelocytic leukaemia in the Australasian Leukaemia and Lymphoma Group (ALLG) APML4 study: a non-randomised phase 2 trial. Lancet Haematol. 2015; 2(9):e357-e366.

42. Lo-Coco F, Di Donato L, Schlenk RF. Targeted therapy alone for acute promyelocytic leukemia. N Engl J Med. 2016;374(12):1197-1198.

43. Drapkin RL, Gee TS, Dowling MD, et al. Prophylactic heparin therapy in acute promyelocytic leukemia. Cancer. 1978;41(6):2484-2490.

44. Didisheim P, Trombold JS, Vandervoort RLE, Mibashan RS. Acute promyelocytic leukemia with fibrinogen and factor $\mathrm{V}$ deficiencies. Blood. 1964;23(6):717-728.

45. Rosenthal RL. Acute promyelocytic leukemia associated with hypofibrinogenemia. Blood. 1963;21(4):495-508.

46. Bernard J, Weil M, Boiron M, Jacquillat C, Flandrin G, Gemon M-F. Acute promyelocytic leukemia: results of treatment by daunorubicin. Blood. 1973;41(4):489-496.

47. Collins AJ, Bloomfield CD, Peterson BA, McKenna RW, Edson J. Acute promyelocytic leukemia: management of the coagulopathy during daunorubicin-prednisone remission induction. Arch Intern Med. 1978; 138(11):1677-1680.

48. Marty M, Ganem G, Fischer J, et al. Leucemie aigue promyelocytaire; etude retrospective de 119 malades traits par Daunorubicine [Acute promyelocytic leukemia: retrospective study of 119 patients treated with daunorubicin]. Nouv Rev Fr Hematol. 1984;26(6):371-378. French. 
49. Cordonnier C, Vernant JP, Brun B, et al. Acute promyelocytic leukemia in 57 previously untreated patients. Cancer. 1985;55(1): $18-25$.

50. Petti MC, Avvisati G, Amadori S, et al. Acute promyelocytic leukemia: clinical aspects and results of treatment in 62 patients. Haematologica. 1987;72(2):151-155.

51. Sanz MA, Jarque I, Martín G, et al. Acute promyelocytic leukemia. Therapy results and prognostic factors. Cancer. 1988;61(1):7-13.

52. Cunningham I, Gee T, Reich L, Kempin S, Naval A, Clarkson B. Acute promyelocytic leukemia: treatment results during a decade at Memorial Hospital. Blood. 1989;73(5):1116-1122.

53. Avvisati G, Mandelli F, Petti MC, et al. Idarubicin (4-demethoxydaunorubicin) as single agent for remission induction of previously untreated acute promyelocytic leukemia: a pilot study of the Italian cooperative group GIMEMA. Eur J Haematol. 1990;44(4):257-260.

54. Fenaux $P$, Tertian $G$, Castaigne $S$, et al. A randomized trial of amsacrine and rubidazone in 39 patients with acute promyelocytic leukemia. J Clin Oncol. 1991;9(9):1556-1561.

55. Fenaux P, Pollet JP, Vandenbossche-Simon L, et al. Treatment of acute promyelocytic leukemia: a report of 70 cases. Leuk Lymphoma. 1991;4(4): 239-248.

56. Kantarjian HM, Keating MJ, Walters RS, et al. Acute promyelocytic leukemia. Am J Med. 1986;80(5):789-797.

57. Head D, Kopecky KJ, Weick J, et al. Effect of aggressive daunomycin therapy on survival in acute promyelocytic leukemia. Blood. 1995;86(5): 1717-1728.

58. Avvisati G, Petti MC, Lo-Coco F, et al; GIMEMA (Gruppo Italiano Malattie Ematologiche dell'Adulto) Italian Cooperative Group. Induction therapy with idarubicin alone significantly influences event-free survival duration in patients with newly diagnosed hypergranular acute promyelocytic leukemia: final results of the GIMEMA randomized study LAP 0389 with 7 years of minimal follow-up. Blood. 2002;100(9): 3141-3146.

59. Breitman TR, Selonick SE, Collins SJ. Induction of differentiation of the human promyelocytic leukemia cell line (HL-60) by retinoic acid. Proc Natl Acad Sci US A. 1980;77(5):2936-2940.

60. Breitman TR, Collins SJ, Keene BR. Terminal differentiation of human promyelocytic leukemic cells in primary culture in response to retinoic acid. Blood. 1981;57(6):1000-1004.

61. Chomienne C, Ballerini P, Balitrand N, et al. All-trans retinoic acid in acute promyelocytic leukemias. II. In vitro studies: structure-function relationship. Blood. 1990;76(9):1710-1717.

62. Wang Z-Y, Chen Z. Acute promyelocytic leukemia: from highly fatal to highly curable. Blood. 2008;111(5):2505-2515.

63. Raelson J, Nervi C, Rosenauer A, et al. The PML/RAR alpha oncoprotein is a direct molecular target of retinoic acid in acute promyelocytic leukemia cells. Blood. 1996;88(8):2826-2832.

64. Yoshida H, Kitamura K, Tanaka K, et al. Accelerated degradation of PML-retinoic acid receptor alpha (PML-RARA) oncoprotein by alltrans-retinoic acid in acute promyelocytic leukemia: possible role of the proteasome pathway. Cancer Res. 1996;56(13):2945-2948.

65. Nervi C, Ferrara FF, Fanelli M, et al. Caspases mediate retinoic acid-induced degradation of the acute promyelocytic leukemia PML/ RARalpha fusion protein. Blood. 1998;92(7):2244-2251.

66. Zhu J, Gianni M, Kopf E, et al. Retinoic acid induces proteasomedependent degradation of retinoic acid receptor alpha (RARalpha) and oncogenic RARalpha fusion proteins. Proc Natl Acad Sci US A. 1999; 96(26):14807-14812.

67. Nasr R, Guillemin MC, Ferhi O, et al. Eradication of acute promyelocytic leukemia-initiating cells through PML-RARA degradation. Nat Med. 2008;14(12):1333-1342.

68. Lane AA, Ley TJ. Neutrophil elastase cleaves PML-RARalpha and is important for the development of acute promyelocytic leukemia in mice. Cell. 2003;115(3):305-318.

69. Huang M, Ye Y, Chen S, et al. Use of all-trans retinoic acid in the treatment of acute promyelocytic leukemia. Blood. 1988;72(2): $567-572$.
70. Degos L, Chomienne C, Daniel MT, et al. Treatment of first relapse in acute promyelocytic leukaemia with all-trans retinoic acid. Lancet. 1990;336(8728):1440-1441.

71. Castaigne S, Chomienne C, Daniel MT, et al. All-trans retinoic acid as a differentiation therapy for acute promyelocytic leukemia. I. Clinical results. Blood. 1990;76(9):1704-1709.

72. Warrell RP Jr, Maslak P, Eardley A, Heller G, Miller WH Jr, Frankel SR. Treatment of acute promyelocytic leukemia with all-trans retinoic acid: an update of the New York experience. Leukemia. 1994;8(6): 929-933.

73. Chen ZX, Xue YQ, Zhang R, et al. A clinical and experimental study on all-trans retinoic acid-treated acute promyelocytic leukemia patients. Blood. 1991;78(6):1413-1419.

74. Frankel SR, Eardley A, Lauwers G, Weiss M, Warrell RP Jr. The "retinoic acid syndrome" in acute promyelocytic leukemia. Ann Intern Med. 1992;117(4):292-296.

75. De Botton S, Dombret H, Sanz M, et al. Incidence, clinical features, and outcome of all trans-retinoic acid syndrome in 413 cases of newly diagnosed acute promyelocytic leukemia. The European APL Group. Blood. 1998;92(8):2712-2718.

76. Luesink M, Pennings JLA, Wissink WM, et al. Chemokine induction by all-trans retinoic acid and arsenic trioxide in acute promyelocytic leukemia: triggering the differentiation syndrome. Blood. 2009;114(27):5512-5521.

77. Sanz MA, Montesinos P. How we prevent and treat differentiation syndrome in patients with acute promyelocytic leukemia. Blood. 2014;123(18):2777-2782

78. Sanz MA, Grimwade D, Tallman MS, et al. Management of acute promyelocytic leukemia: recommendations from an expert panel on behalf of the European LeukemiaNet. Blood. 2009;113(9): 1875-1891.

79. Wiley JS, Firkin FC. Reduction of pulmonary toxicity by prednisolone prophylaxis during all-trans retinoic acid treatment of acute promyelocytic leukemia. Australian Leukaemia Study Group. Leukemia. 1995; 9(5):774-778.

80. Kelaidi C, Chevret S, De Botton S, et al. Improved outcome of acute promyelocytic leukemia with high WBC counts over the last 15 years: The European APL Group Experience. J Clin Oncol. 2009;27(16): 2668-2676.

81. Montesinos P, Bergua JM, Vellenga E, et al. Differentiation syndrome in patients with acute promyelocytic leukemia treated with all-trans retinoic acid and anthracycline chemotherapy: characteristics, outcome, and prognostic factors. Blood. 2009;113(4):775-783.

82. Fenaux P, Chevret S, Guerci A, et al. Long-term follow-up confirms the benefit of all-trans retinoic acid in acute promyelocytic leukemia. European APL group. Leukemia. 2000;14(8):1371-1377.

83. Fenaux P, Le Deley MC, Castaigne S, et al. Effect of all transretinoic acid in newly diagnosed acute promyelocytic leukemia. Results of a multicenter randomized trial. European APL 91 Group. Blood. 1993; 82(11):3241-3249.

84. Fenaux $\mathrm{P}$, Chastang $\mathrm{C}$, Chevret $\mathrm{S}$, et al. A randomized comparison of all transretinoic acid (ATRA) followed by chemotherapy and ATRA plus chemotherapy and the role of maintenance therapy in newly diagnosed acute promyelocytic leukemia. Blood. 1999;94(4):1192-1200.

85. Sanz MA, Martín G, Rayón C, et al. A modified AIDA protocol with anthracycline-based consolidation results in high antileukemic efficacy and reduced toxicity in newly diagnosed PML/RAR $\alpha$-positive acute promyelocytic leukemia. Blood. 1999;94(9):3015-3021.

86. Burnett AK, Grimwade D, Solomon E, Wheatley K, Goldstone AH. Presenting white blood cell count and kinetics of molecular remission predict prognosis in acute promyelocytic leukemia treated with all-trans retinoic acid: result of the randomized MRC trial. Blood. 1999;93(12):4131-4143.

87. Asou N, Adachi K, Tamura J, et al. Analysis of prognostic factors in newly diagnosed acute promyelocytic leukemia treated with all-trans retinoic acid and chemotherapy. Japan Adult Leukemia Study Group. J Clin Oncol. 1998;16(1):78-85. 
88. Tallman MS, Andersen JW, Schiffer CA, et al. All-trans-retinoic acid in acute promyelocytic leukemia. [Erratum appears in $N$ Engl J Med. 1997;337(22):1639]. N Engl J Med. 1997;337(15): 1021-1028.

89. Mandelli F, Diverio D, Avvisati G, et al. Molecular remission in PML/ RAR $\alpha$-positive acute promyelocytic leukemia by combined all-trans retinoic acid and idarubicin (AIDA) therapy. Blood. 1997;90(3): 1014-1021.

90. Avvisati G, Lo Coco F, Diverio D, et al. AIDA (all-trans retinoic acid + idarubicin) in newly diagnosed acute promyelocytic leukemia: a Gruppo Italiano Malattie Ematologiche Maligne dell'Adulto (GIMEMA) pilot study. Blood. 1996;88(4):1390-1398.

91. Iland H, Bradstock K, Seymour J, et al; Australasian Leukaemia and Lymphoma Group. Results of the APML3 trial incorporating all-trans-retinoic acid and idarubicin in both induction and consolidation as initial therapy for patients with acute promyelocytic leukemia. Haematologica. 2012;97(2):227-234.

92. Sanz MA, Coco FL, Martín G, et al. Definition of relapse risk and role of nonanthracycline drugs for consolidation in patients with acute promyelocytic leukemia: a joint study of the PETHEMA and GIMEMA cooperative groups. Blood. 2000;96(4):1247-1253.

93. Lo-Coco F, Avvisati G, Vignetti M, et al; Italian GIMEMA Cooperative Group. Front-line treatment of acute promyelocytic leukemia with AIDA induction followed by risk-adapted consolidation for adults younger than 61 years: results of the AIDA-2000 trial of the GIMEMA Group. Blood. 2010;116(17):3171-3179.

94. Sanz MA, Martin G, Gonzalez M, et al. Risk-adapted treatment of acute promyelocytic leukemia with all-trans-retinoic acid and anthracycline monochemotherapy: a multicenter study by the PETHEMA group. Blood. 2004;103(4):1237-1243.

95. Adès L, Chevret S, Raffoux E, et al; European APL Group. Longterm follow-up of European APL 2000 trial, evaluating the role of cytarabine combined with ATRA and Daunorubicin in the treatment of nonelderly APL patients. Am J Hematol. 2013;88(7):556-559.

96. Ades L, Sanz MA, Chevret S, et al. Treatment of newly diagnosed acute promyelocytic leukemia (APL): a comparison of French-BelgianSwiss and PETHEMA results. Blood. 2008;111(3):1078-1084.

97. Sanz MA, Martin G, Lo Coco F. Choice of chemotherapy in induction, consolidation and maintenance in acute promyelocytic leukaemia. Best Prac Clin Haematol. 2003;16(3):433-451.

98. Burnett AK, Hills RK, Grimwade D, et al; United Kingdom National Cancer Research Institute Acute Myeloid Leukaemia Subgroup. Inclusion of chemotherapy in addition to anthracycline in the treatment of acute promyelocytic leukaemia does not improve outcomes: results of the MRC AML15 trial. Leukemia. 2013;27(4):843-851.

99. Montesinos P, Gonzalez JD, Gonzalez J, et al. Therapy-related myeloid neoplasms in patients with acute promyelocytic leukemia treated with all-trans-retinoic acid and anthracycline-based chemotherapy. J Clin Oncol. 2010;28(24):3872-3879.

100. Batzios C, Hayes LA, He SZ, et al. Secondary clonal cytogenetic abnormalities following successful treatment of acute promyelocytic leukemia. [Erratum appears in Am J Hematol. 2010;85(7):550]. Am J Hematol. 2009;84(11):715-719.

101. Lobe I, Rigal-Huguet F, Vekhoff A, et al; European APL Group Experience. Myelodysplastic syndrome after acute promyelocytic leukemia: the European APL group experience. Leukemia. 2003;17(8): 1600-1604.

102. Zompi S, Viguie F. Therapy-related acute myeloid leukemia and myelodysplasia after successful treatment of acute promyelocytic leukemia. Leuk Lymphoma. 2002;43(2):275-280.

103. Latagliata R, Petti MC, Fenu S, et al. Therapy-related myelodysplastic syndrome-acute myelogenous leukemia in patients treated for acute promyelocytic leukemia: an emerging problem. Blood. 2002;99(3):822-824.

104. Garcia-Manero G, Kantarjian H, Kornblau S, Estey E. Therapyrelated myelodysplastic syndrome or acute myelogenous leukemia in patients with acute promyelocytic leukemia (APL). Leukemia. 2002;16(9):1888.
105. Andersen MK, Pedersen-Bjergaard J. Therapy-related MDS and AML in acute promyelocytic leukemia. Blood. 2002;100:1928-1930.

106. Pellicori P, Calicchia A, Lococo F, Cimino G, Torromeo C. Subclinical anthracycline cardiotoxicity in patients with acute promyelocytic leukemia in long-term remission after the AIDA protocol. Congest Heart Fail. 2012;18(4):217-221.

107. Thomas X, Le QH, Fiere D. Anthracycline-related toxicity requiring cardiac transplantation in long-term disease-free survivors with acute promyelocytic leukemia. Ann Hematol. 2002;81(9):504-507.

108. Avvisati G. Newly diagnosed acute promyelocytic leukemia. Mediterr J Hematol Infect Dis. 2011;3(1):e2011064.

109. Byrns MC, Penning TM. Chapter 67. Environmental toxicology: carcinogens and heavy metals. In: Brunton LL, Chabner BA, Knollmann BC, editors. Goodman and Gilman's The Pharmacological Basis of Therapeutics, 12e. New York, NY: The McGraw-Hill Companies; 2011.

110. Chen SJ, Zhou GB, Zhang XW, Mao JH, de The H, Chen Z. From an old remedy to a magic bullet: molecular mechanisms underlying the therapeutic effects of arsenic in fighting leukemia. Blood. 2011; 117(24):6425-6437.

111. Forkner CE, Scott T. Arsenic as a therapeutic agent in chronic myelogenous leukemia: preliminary report. J Am Med Assoc. 1931;97(1):3-5.

112. Kwong YL, Todd D. Delicious poison: arsenic trioxide for the treatment of leukemia. Blood. 1997;89(9):3487-3487.

113. Shen ZX, Chen GQ, Ni JH, et al. Use of arsenic trioxide (As2O3) in the treatment of acute promyelocytic leukemia (APL): II. Clinical efficacy and pharmacokinetics in relapsed patients. Blood. 1997;89(9): 3354-3360.

114. Chen GQ, Shi XG, Tang W, et al. Use of arsenic trioxide (As2O3) in the treatment of acute promyelocytic leukemia (APL): I. As2O3 exerts dosedependent dual effects on APL cells. Blood. 1997;89(9):3345-3353.

115. de The H, Le Bras M, Lallemand-Breitenbach V. The cell biology of disease: acute promyelocytic leukemia, arsenic, and PML bodies. J Cell Biol. 2012;198(1):11-21.

116. Jeanne M, Lallemand-Breitenbach V, Ferhi O, et al. PML/RARA oxidation and arsenic binding initiate the antileukemia response of As2O3. Cancer Cell. 2010;18(1):88-98.

117. Zhang X-W, Yan X-J, Zhou Z-R, et al. Arsenic trioxide controls the fate of the PML-RARalpha oncoprotein by directly binding PML.[Erratum appears in Science. 2010;328(5981):974]. Science. 2010;328(5975):240-243.

118. Lallemand-Breitenbach V, Jeanne M, Benhenda S, et al. Arsenic degrades PML or PML-RARalpha through a SUMO-triggered RNF4/ ubiquitin-mediated pathway. Nat Cell Biol. 2008;10(5):547-555.

119. Tatham MH, Geoffroy M-C, Shen L, et al. RNF4 is a poly-SUMOspecific E3 ubiquitin ligase required for arsenic-induced PML degradation. Nat Cell Biol. 2008;10(5):538-546.

120. dos Santos GA, Kats L, Pandolfi PP. Synergy against PML-RARa: targeting transcription, proteolysis, differentiation, and self-renewal in acute promyelocytic leukemia. J Exp Med. 2013;210(13):2793-2802.

121. Lallemand-Breitenbach V, Guillemin MC, Janin A, et al. Retinoic acid and arsenic synergize to eradicate leukemic cells in a mouse model of acute promyelocytic leukemia. J Exp Med. 1999;189(7):1043-1052.

122. Rego EM, He LZ, Warrell RP Jr, Wang ZG, Pandolfi PP. Retinoic acid (RA) and As2O3 treatment in transgenic models of acute promyelocytic leukemia (APL) unravel the distinct nature of the leukemogenic process induced by the PML-RARalpha and PLZF-RARalpha oncoproteins. Proc Natl Acad Sci U S A. 2000;97(18):10173-10178.

123. Soignet SL, Frankel SR, Douer D, et al. United States multicenter study of arsenic trioxide in relapsed acute promyelocytic leukemia. J Clin Oncol. 2001;19(18):3852-3860.

124. Soignet SL, Maslak P, Wang ZG, et al. Complete remission after treatment of acute promyelocytic leukemia with arsenic trioxide. N Engl J Med. 1998;339(19):1341-1348.

125. Au WY, Lie AKW, Chim CS, et al. Arsenic trioxide in comparison with chemotherapy and bone marrow transplantation for the treatment of relapsed acute promyelocytic leukaemia. Ann Oncol. 2003; 14(5):752-757. 
126. Lazo G, Kantarjian H, Estey E, Thomas D, O’Brien S, Cortes J. Use of arsenic trioxide (As2O3) in the treatment of patients with acute promyelocytic leukemia: the M. D. Anderson experience. Cancer. 2003; 97(9):2218-2224.

127. Niu C, Yan H, Yu T, et al. Studies on treatment of acute promyelocytic leukemia with arsenic trioxide: remission induction, follow-up, and molecular monitoring in 11 newly diagnosed and 47 relapsed acute promyelocytic leukemia patients. Blood. 1999;94(10):3315-3324.

128. Raffoux E, Rousselot P, Poupon J, et al. Combined treatment with arsenic trioxide and all-trans-retinoic acid in patients with relapsed acute promyelocytic leukemia. J Clin Oncol. 2003;21(12): 2326-2334.

129. Shigeno K, Naito K, Sahara N, et al. Arsenic trioxide therapy in relapsed or refractory Japanese patients with acute promyelocytic leukemia: updated outcomes of the phase II study and postremission therapies. Int J Hematol. 2005;82(3):224-229.

130. Thomas X, Pigneux A, Raffoux E, Huguet F, Caillot D, Fenaux P Superiority of an arsenic trioxide-based regimen over a historic control combining all-trans retinoic acid plus intensive chemotherapy in the treatment of relapsed acute promyelocytic leukemia. Haematologica. 2006;91(7):996-997.

131. Shen Z-X, Shi Z-Z, Fang J, et al. All-trans retinoic acid/As2O3 combination yields a high quality remission and survival in newly diagnosed acute promyelocytic leukemia. Proc Natl Acad Sci US A. 2004;101(15): 5328-5335.

132. Hu J, Liu Y-F, Wu C-F, et al. Long-term efficacy and safety of all-trans retinoic acid/arsenic trioxide-based therapy in newly diagnosed acute promyelocytic leukemia. Proc Natl Acad Sci U S A. 2009;106(9):3342-3347.

133. Dai C-W, Zhang G-S, Shen J-K, et al. Use of all-trans retinoic acid in combination with arsenic trioxide for remission induction in patients with newly diagnosed acute promyelocytic leukemia and for consolidation/maintenance in CR patients. [Erratum appears in Acta Haematol. 2009;121(4):243]. Acta Haematol. 2009;121(1):1-8.

134. Mathews V, George B, Lakshmi KM, et al. Single-agent arsenic trioxide in the treatment of newly diagnosed acute promyelocytic leukemia: durable remissions with minimal toxicity. Blood. 2006;107(7): 2627-2632.

135. Ghavamzadeh A, Alimoghaddam K, Ghaffari SH, et al. Treatment of acute promyelocytic leukemia with arsenic trioxide without ATRA and/or chemotherapy. Ann Oncol. 2006;17(1):131-134.

136. Ghavamzadeh A, Alimoghaddam K, Rostami S, et al. Phase II study of single-agent arsenic trioxide for the front-line therapy of acute promyelocytic leukemia. J Clin Oncol. 2011;29(20):2753-2757.

137. Mathews V, George B, Chendamarai E, et al. Single-agent arsenic trioxide in the treatment of newly diagnosed acute promyelocytic leukemia: long-term follow-up data. J Clin Oncol. 2010;28(24): 3866-3871.

138. Leung J, Pang A, Yuen W-H, Kwong Y-L, Tse EWC. Relationship of expression of aquaglyceroporin 9 with arsenic uptake and sensitivity in leukemia cells. Blood. 2007;109(2):740-746.

139. Ravandi F, Estey E, Jones D, et al. Effective treatment of acute promyelocytic leukemia with all-trans-retinoic acid, arsenic trioxide, and gemtuzumab ozogamicin. J Clin Oncol. 2009;27(4):504-510.

140. National Comprehensive Cancer Network [homepage on the Internet]. Clinical Practice Guidelines in Oncology; 2016. Available from: http:// www.nccn.org/. Accessed January 27, 2017.

141. Seftel MD, Barnett MJ, Couban S, et al. A Canadian consensus on the management of newly diagnosed and relapsed acute promyelocytic leukemia in adults. Curr Oncol. 2014;21(5):234-250.

142. Platzbecker U, Avvisati G, Cicconi L, et al. Improved outcomes with retinoic acid and arsenic trioxide compared with retinoic acid and chemotherapy in non-high-risk acute promyelocytic leukemia: final results of the randomized Italian-German APL0406 trial. J Clin Oncol. 2017;35(6):605-612.

143. Iland HJ, Seymour JF. Role of arsenic trioxide in acute promyelocytic leukemia. Curr Treat Options Oncol. 2013;14(2):170-184.
144. Eghtedar A, Rodriguez I, Kantarjian H, et al. Incidence of secondary neoplasms in patients with acute promyelocytic leukemia treated with all-trans retinoic acid plus chemotherapy or with all-trans retinoic acid plus arsenic trioxide. Leuk Lymphoma. 2015;56(5):1342-1345.

145. Zhu H, Hu J, Chen L, et al. The 12-year follow-up of survival, chronic adverse effects, and retention of arsenic in patients with acute promyelocytic leukemia. Blood. 2016;128:1525-1528.

146. Firkin F. Oral administration of arsenic trioxide in the treatment of acute promyelocytic leukaemia and accelerated phase chronic myeloid leukaemia: an Australian single-centre study. Intern Med J. 2012; 42(8):948-952.

147. Au W-Y, Kumana CR, Lee HKK, et al. Oral arsenic trioxide-based maintenance regimens for first complete remission of acute promyelocytic leukemia: a 10-year follow-up study. Blood. 2011;118(25): 6535-6543.

148. Siu C-W, Au W-Y, Yung C, et al. Effects of oral arsenic trioxide therapy on QT intervals in patients with acute promyelocytic leukemia: implications for long-term cardiac safety. Blood. 2006;108(1): $103-106$

149. Au WY, Li C-K, Lee V, et al. Oral arsenic trioxide for relapsed acute promyelocytic leukemia in pediatric patients. Pediatr Blood Cancer. 2012;58(4):630-632.

150. Zhu H-H, Wu D-P, Jin J, et al. Oral tetra-arsenic tetra-sulfide formula versus intravenous arsenic trioxide as first-line treatment of acute promyelocytic leukemia: a multicenter randomized controlled trial. J Clin Oncol. 2013;31(33):4215-4221.

151. Zhu H-H, Wu D-P, Jin J, et al. Long-term survival of acute promyelocytic leukaemia patients treated with arsenic and retinoic acid. $\mathrm{Br} J$ Haematol. 2016;174(5):820-822.

152. Wang L, Zhou G-B, Liu P, et al. Dissection of mechanisms of Chinese medicinal formula Realgar-Indigo naturalis as an effective treatment for promyelocytic leukemia. Proc Natl Acad Sci US A. 2008; 105(12):4826-4831.

153. Avvisati G, Lo-Coco F, Paoloni FP, et al; GIMEMA, AIEOP, and EORTC Cooperative Groups. AIDA 0493 protocol for newly diagnosed acute promyelocytic leukemia: very long-term results and role of maintenance. Blood. 2011;117(18):4716-4725.

154. Ades L, Guerci A, Raffoux E, et al; European APL Group. Very longterm outcome of acute promyelocytic leukemia after treatment with all-trans retinoic acid and chemotherapy: the European APL Group experience. Blood. 2010;115(9):1690-1696.

155. Asou N, Kishimoto Y, Kiyoi H, et al; Japan Adult Leukemia Study Group. A randomized study with or without intensified maintenance chemotherapy in patients with acute promyelocytic leukemia who have become negative for PML-RARalpha transcript after consolidation therapy: the Japan Adult Leukemia Study Group (JALSG) APL97 study. Blood. 2007;110(1):59-66.

156. Tallman MS, Andersen JW, Schiffer CA, et al. All-trans retinoic acid in acute promyelocytic leukemia: long-term outcome and prognostic factor analysis from the North American Intergroup protocol. Blood. 2002;100(13):4298-4302.

157. Muchtar E, Vidal L, Ram R, Gafter-Gvili A, Shpilberg O, Raanani P. The role of maintenance therapy in acute promyelocytic leukemia in the first complete remission. Cochrane Database Syst Rev. 2013 (3):CD009594.

158. Gale RE, Hills R, Pizzey AR, et al; NCRI Adult Leukaemia Working Party. Relationship between FLT3 mutation status, biologic characteristics, and response to targeted therapy in acute promyelocytic leukemia. Blood. 2005;106(12):3768-3776.

159. Beitinjaneh A, Jang S, Roukoz H, Majhail NS. Prognostic significance of FLT3 internal tandem duplication and tyrosine kinase domain mutations in acute promyelocytic leukemia: a systematic review. Leuk Res. 2010;34(7):831-836.

160. Barragan E, Montesinos P, Camos M, et al; PETHEMA; HOVON Groups. Prognostic value of FLT3 mutations in patients with acute promyelocytic leukemia treated with all-trans retinoic acid and anthracycline monochemotherapy. Haematologica. 2011;96(10):1470-1477. 
161. Schnittger S, Bacher U, Haferlach C, Kern W, Alpermann T, Haferlach T. Clinical impact of FLT3 mutation load in acute promyelocytic leukemia with t(15;17)/PML-RARA. Haematologica. 2011;96(12):1799-1807.

162. Kutny MA, Moser BK, Laumann K, et al. FLT3 mutation status is a predictor of early death in pediatric acute promyelocytic leukemia: a report from the Children's Oncology Group. Pediatr Blood Cancer. 2012;59(4):662-667.

163. Cicconi L, Divona M, Ciardi C, et al. PML-RAR $\alpha$ kinetics and impact of FLT3-ITD mutations in newly diagnosed acute promyelocytic leukemia treated with ATRA and ATO or ATRA and chemotherapy. Leukemia. 2016;30:1987-1992.

164. Testa U, Lo-Coco F. Prognostic factors in acute promyelocytic leukemia: strategies to define high-risk patients. Ann Hematol. 2016;95(5): 673-680.

165. Lengfelder E, Hanfstein B, Haferlach C, et al; German Acute Myeloid Leukemia Cooperative Group (AMLCG). Outcome of elderly patients with acute promyelocytic leukemia: results of the German Acute Myeloid Leukemia Cooperative Group. Ann Hematol. 2013;92(1):41-52.

166. Lengfelder E, Haferlach C, Saussele S, et al; German AML Cooperative Group. High dose ara-C in the treatment of newly diagnosed acute promyelocytic leukemia: long-term results of the German AMLCG. Leukemia. 2009;23(12):2248-2258.

167. McClellan JS, Kohrt HE, Coutre S, et al. Treatment advances have not improved the early death rate in acute promyelocytic leukemia. Haematologica. 2012;97(1):133-136.

168. Micol JB, Raffoux E, Boissel N, et al. Management and treatment results in patients with acute promyelocytic leukaemia (APL) not enrolled in clinical trials. Eur J Cancer. 2014;50(6):1159-1168.

169. Park JH, Qiao B, Panageas KS, et al. Early death rate in acute promyelocytic leukemia remains high despite all-trans retinoic acid. Blood. 2011;118(5):1248-1254.

170. Yanada M, Matsushita T, Asou N, et al. Severe hemorrhagic complications during remission induction therapy for acute promyelocytic leukemia: incidence, risk factors, and influence on outcome. Eur $J$ Haematol. 2007;78(3):213-219.

171. de la Serna J, Montesinos P, Vellenga E, et al. Causes and prognostic factors of remission induction failure in patients with acute promyelocytic leukemia treated with all-trans retinoic acid and idarubicin. Blood. 2008;111(7):3395-3402.

172. Breen KA, Grimwade D, Hunt BJ. The pathogenesis and management of the coagulopathy of acute promyelocytic leukaemia. Br J Haematol. 2012;156(1):24-36.

173. Kwaan HC, Cull EH. The coagulopathy in acute promyelocytic leukaemia - what have we learned in the past twenty years. Best Pract Res Clin Haematol. 2014;27(1):11-18.

174. Menell JS, Cesarman GM, Jacovina AT, McLaughlin MA, Lev EA, Hajjar KA. Annexin II and bleeding in acute promyelocytic leukemia. N Engl J Med. 1999;340(13):994-1004.

175. Ikezoe T, Takeuchi A, Isaka M, et al. Recombinant human soluble thrombomodulin safely and effectively rescues acute promyelocytic leukemia patients from disseminated intravascular coagulation. Leuk Res. 2012;36(11):1398-1402.

176. Kawano N, Kuriyama T, Yoshida S, et al. Clinical features and treatment outcomes of six patients with disseminated intravascular coagulation resulting from acute promyelocytic leukemia and treated with recombinant human soluble thrombomodulin at a single institution. Intern Med. 2013;52(1):55-62.

177. Saito A, Okamoto Y, Seki Y, et al. DIC complicating APL successfully treated with recombinant thrombomodulin alfa. $J$ Pediatr Hematol Oncol. 2016;38(6):e189-e190.

178. Meijers JC, Oudijk EJ, Mosnier LO, et al. Reduced activity of TAFI (thrombin-activatable fibrinolysis inhibitor) in acute promyelocytic leukaemia. Br J Haematol. 2000;108(3):518-523.

179. Rego EM, Kim HT, Ruiz-Arguelles GJ, et al. Improving acute promyelocytic leukemia (APL) outcome in developing countries through networking, results of the International Consortium on APL. Blood. 2013;121(11):1935-1943.
180. Testi AM, D'Angio M, Locatelli F, Pession A, Lo Coco F. Acute promyelocytic leukemia (APL): comparison between children and adults. Mediterr J Hematol Infect Dis. 2014;6(1):e2014032.

181. Bally C, Fadlallah J, Leverger G, et al. Outcome of acute promyelocytic leukemia (APL) in children and adolescents: an analysis in two consecutive trials of the European APL Group. J Clin Oncol. 2012; 30(14):1641-1646.

182. de Botton S, Coiteux V, Chevret S, et al. Outcome of childhood acute promyelocytic leukemia with all-trans-retinoic acid and chemotherapy. J Clin Oncol. 2004;22(8):1404-1412.

183. Mann G, Reinhardt D, Ritter J, et al. Treatment with all-trans retinoic acid in acute promyelocytic leukemia reduces early deaths in children. Ann Hematol. 2001;80(7):417-422.

184. Ortega JJ, Madero L, Martin G, et al; German AML Cooperative Group. Treatment with all-trans retinoic acid and anthracycline monochemotherapy for children with acute promyelocytic leukemia: a multicenter study by the PETHEMA Group. J Clin Oncol. 2005;23(30): 7632-7640.

185. Testi AM, Biondi A, Lo Coco F, et al. GIMEMA-AIEOPAIDA protocol for the treatment of newly diagnosed acute promyelocytic leukemia (APL) in children. Blood. 2005;106(2):447-453.

186. Castaigne $\mathrm{S}$, Lefebvre $\mathrm{P}$, Chomienne $\mathrm{C}$, et al. Effectiveness and pharmacokinetics of low-dose all-trans retinoic acid $(25 \mathrm{mg} / \mathrm{m} 2)$ in acute promyelocytic leukemia. Blood. 1993;82(12):3560-3563.

187. Creutzig U, van den Heuvel-Eibrink MM, Gibson B, etal; AML Committee of the International BFM Study Group. Diagnosis and management of acute myeloid leukemia in children and adolescents: recommendations from an international expert panel. Blood. 2012;120(16):3187-3205.

188. Creutzig U, Zimmermann M, Dworzak M, et al. Favourable outcome of patients with childhood acute promyelocytic leukaemia after treatment with reduced cumulative anthracycline doses. Br J Haematol. 2010;149(3):399-409.

189. Imaizumi M, Tawa A, Hanada R, et al. Prospective study of a therapeutic regimen with all-trans retinoic acid and anthracyclines in combination of cytarabine in children with acute promyelocytic leukaemia: the Japanese childhood acute myeloid leukaemia cooperative study. Br J Haematol. 2011;152(1):89-98.

190. George B, Mathews V, PoonkuzhaliB, Shaji RV, Srivastava A, Chandy M. Treatment of children with newly diagnosed acute promyelocytic leukemia with arsenic trioxide: a single center experience. Leukemia. 2004;18(10):1587-1590.

191. Zhou J, Zhang Y, Li J, et al. Single-agent arsenic trioxide in the treatment of children with newly diagnosed acute promyelocytic leukemia. Blood. 2010;115(9):1697-1702.

192. Cheng Y, Zhang L, Wu J, Lu A, Wang B, Liu G. Long-term prognosis of childhood acute promyelocytic leukaemia with arsenic trioxide administration in induction and consolidation chemotherapy phases: a single-centre experience. Eur J Haematol. 2013;91(6):483-489.

193. Milojkovic D, Apperley JF. How I treat leukemia during pregnancy. Blood. 2014;123(7):974-984.

194. Culligan DJ, Merriman L, Kell J, et al. The management of acute promyelocytic leukemia presenting during pregnancy. Clin Leuk. 2007;1(3): 183-191.

195. Naujokas MF, Anderson B, Ahsan H, et al. The broad scope of health effects from chronic arsenic exposure: update on a worldwide public health problem. Environ Health Perspect. 2013;121(3):295-302.

196. Warrell RP Jr, Frankel SR, Miller WH Jr, et al. Differentiation therapy of acute promyelocytic leukemia with tretinoin (all-trans-retinoic acid). N Engl J Med. 1991;324(20):1385-1393.

197. Siu BL, Alonzo MR, Vargo TA, Fenrich AL. Transient dilated cardiomyopathy in a newborn exposed to idarubicin and all-trans-retinoic acid (ATRA) early in the second trimester of pregnancy. Int $J$ Gynecol Cancer. 2002;12(4):399-402.

198. Terada Y, Shindo T, Endoh A, Watanabe M, Fukaya T, Yajima A. Fetal arrhythmia during treatment of pregnancy-associated acute promyelocytic leukemia with all-trans retinoic acid and favorable outcome. Leukemia. 1997;11(3):454-455. 
OncoTargets and Therapy

\section{Publish your work in this journal}

OncoTargets and Therapy is an international, peer-reviewed, open access journal focusing on the pathological basis of all cancers, potential targets for therapy and treatment protocols employed to improve the management of cancer patients. The journal also focuses on the impact of management programs and new therapeutic agents and protocols on

patient perspectives such as quality of life, adherence and satisfaction. The manuscript management system is completely online and includes a very quick and fair peer-review system, which is all easy to use. Visit http://www.dovepress.com/testimonials.php to read real quotes from published authors.

Submit your manuscript here: http://www.dovepress.com/oncotargets-and-therapy-journal 